\title{
Desaparación forzada en Colombia: las territorialidades construidas en el departamento de Antoquia entre la materialidad y los significados
}

\section{Forced disappearance in Colombia: the territorylities built in the department of Antoquia between materiality and meanings}

Elena Cifuentes Ortiz* Johan Andrés Avendaño**

Fecha de recibido: 1 de julio de 2020

Fecha de aceptado: 13 de noviembre de 2020

\section{Resumen}

La desaparición forzada es una violencia que en su materialidad configura, construye y produce el espacio geográfico. Así, los análisis espaciales que se hagan de esta, permiten evidenciar que su perpetración hacia el ser que la padece, va más allá de un espacio meramente concebido desde las coordenadas físicas de ubicación de los lugares donde sucede y de los lugares en que son halladas las víctimas desaparecidas en sus restos mortales, su dimensión también sobrepasa los momentos de estos acontecimientos. En este sentido, la materialidad de esta violencia presentará una amplificación compleja en un espacio no absoluto, pues este se relativiza por las relaciones vivenciales experimentadas, mostrando la producción de territorialidades desde las multiplicidades posibles dadas en los territorios.

Palabras clave: desaparición forzada, complejidad relacional, espacio relativo y vivencial, territorialidad.

* Instituto Nacional de Medicina Legal y Ciencias Forenses, Bogotá Colombia, correo electrónico: elenacifuentes86@gmail.com

** Universidad Distrital Francisco José de Caldas, Bogotá, Colombia, correo electrónico: jaavendanoa@correo.udistrital.edu.co 


\section{Abstract}

Enforced disappearance is a violence that in its materiality configures, builds and produces geographic space. Thus, the spatial analyzes that are made of this, make it possible to show that its perpetration towards the being that suffers it, goes beyond a space merely conceived from the physical coordinates of the location of the places where it happens and the places where the victims disappeared in their mortal remains, their dimension also exceeds the moments of these events. In this sense, the materiality of this violence will present a complex amplification in a non-absolute space, since it is relativized by the experiential relations experienced, showing the production of territorialities from the possible multiplicities given in the territories.

Key words: enforced disappearance, relational complexity, relative and experiential space, territoriality.

\section{Introducción}

Intentar una aproximación geográfica de análisis sobre la desaparición forzada, implica tener presente que este tipo de violencia está circunscrita por múltiples particularidades, factores y dimensiones, dinamizadas por la configuración de poderes en sus diferentes espacialidades (Cifuentes y Avendaño, 2020). De igual manera, es importante partir de la intención en su materialidad, pues esta violencia tiene un sentido lógico-sistemático, calculado y doloroso; pues plantea desde una lectura implícita, que una persona es desaparecida para que nunca aparezca, en el interés de impunidad que persigue quien la ejecuta (CNMH, 2016) y es justo ese sentido el que hace que el acercamiento a conclusiones de verdad represente complejos retos, los cuales no desdibujan la producción del espacio que subyace de la complejidad relacional vivencial que propone su materialidad en un espacio geográfico y que en este caso, será el departamento de Antioquia en el noroccidente de Colombia. Considerado como el departamento más victimizado del país, cualquiera que sea la modalidad de violencia con respecto a otro departamento, Antioquia siempre se ubica en el primer lugar en una relación casi de tres a uno (Giraldo, 2015). Esa es la razón principal que llevó a la selección del área de estudio de la siguiente reflexión, sin desconocer que en otros ámbitos es necesario ampliar a otras geografías.

De esta manera, se hablará inicialmente del contexto de 113 personas desaparecidas, aparecidas muertas, ${ }^{1}$ caracterizadas como población centro del

1 El concepto de "personas desaparecidas, aparecidas muertas" se propone a partir de la categoría, "Estado de la desaparición" contenida en el Registro Nacional de Desaparecidos (RND), la cual presenta tres variables de información: “Apareció Vivo", “Apareció Muerto” y "Continúa Desaparecido". Así, la población delimitada objeto del análisis presentado, corresponde con 
presente análisis, en un periodo entre 1993 y 2016. ${ }^{2}$ Mencionando que la categoría sobre la materialidad de la desaparición forzada se entenderá como aquella condición dada por la concreción de esta violencia específicamente en dos hechos: la desaparición de la persona y posterior hallazgo en sus restos mortales (Cifuentes, 2020). Seguido al contexto, se abordarán los movimientos ${ }^{3}$ de esta materialidad en el espacio y en el tiempo desde un análisis multiescalar y singular. Finalmente, se presenta un análisis sobre la configuración de territorialidades a partir de la amplificación espacial de esta violencia desde el espacio y tiempo. Mostrando que las territorialidades derivadas de esta materialidad no se configuran en el espacio y tiempo absolutos, sino relativos a una espacialidad vivida y de complejidad relacional. En suma, no queda la menor duda que la desaparición forzada y todos los matices que las embarga, es un tema de relevancia para la geografía con foco en Colombia, pero con perspectiva a reanimar este tipo de reflexiones a nivel mundial.

\section{Víctimas mortales de la desaparición forzada en Antioquia entre los años 1993 y 2016. Comportamiento de los datos y características de la población}

De acuerdo con los datos históricos para el periodo 1938 a 2015, Colombia presentó un total de 110833 casos de personas desaparecidas (Segura y Ramírez, 2015). De este total, 16516 casos correspondieron al departamento de Antioquia,

personas reportadas inicialmente como desaparecidas y que, a través de las diligencias de búsqueda y recuperación de restos mortales en su mayoría exhumados, su estado final en el RND data como apareció muerto.

2 Esta temporalidad se define a partir del tratamiento metodológico de la información disponible, donde tuvo lugar una depuración de los datos con relación a aquellos que presentaban las variables de interés para el análisis.

3 Según los resultados observados en la espacialización de la información, se establecieron las siguientes categorías para analizarlos: -flujos interdepartamentales: definidos por los acontecimientos de desaparición, sucedidos en diferentes municipios de Antioquia y de hallazgos posteriores, dados en municipios de otros departamentos. -Flujos intermunicipales: definidos por desapariciones dadas en unos municipios antioqueños y posteriores hallazgos en otros municipios antioqueños. Singularidad espacial intramunicipal: esta categoría muestra los comportamientos espaciales de la desaparición y hallazgo de los restos mortales, al interior de los municipios; básicamente expresados en tres circunstancias: una relacionada con las desapariciones y hallazgos dados en el mismo municipio, donde no fue posible profundizar más allá de la escala espacial municipal. La segunda, tendrá que ver con los flujos interveredales: los cuales se definieron con las desapariciones dadas en unas veredas, cuyos hallazgos de los cadáveres se dieron en otras veredas y -Espacialidad puntual veredal: en esta categoría se ubicaron los casos cuyas desapariciones y posteriores hallazgos de los cuerpos, se dieron en la misma vereda. 
de los cuales 5912 se clasificaron como desapariciones presuntamente forzadas y 488 con un estado de aparecidos muertos (RND, 2015). ${ }^{4}$

El comportamiento de las cifras sobre desaparición forzada tanto para Antioquia como para Colombia en general, puede estar en alguna medida, influenciado por los vacíos y subregistro de la información, pues solo hasta el año 2000 con la Ley 589 de 2000, esta práctica fue tipificada como delito y apenas a partir de ésta se empezaron a diseñar e implementar instrumentos para la formulación de política pública, como la creación de la Comisión de Búsqueda de Personas Desaparecidas (CBPD), el RND ${ }^{5}$ y el Mecanismo de Búsqueda Urgente $(\mathrm{MBU})^{6}$, esencialmente para dar cumplimiento a las disposiciones de ley, así como para incluir esta práctica violenta con un sentido propio de delito dentro de la operatividad de la justicia. Antes de la expedición de la norma, la desaparición forzada era tratada tan sólo como un delito de secuestro o de homicidio minimizando peligrosamente su complejidad.

Entender estos contextos en términos de tiempo y de desarrollo del conflicto en el país, es reconocer que parte de las víctimas de desaparición forzada como los hechos asociados, quedaron sin posibilidad de registrarse o sin posibilidad de conocerse, pues a mayor tiempo, la posibilidad de recuperar información para la alimentación de un sistema como lo es el Registro Nacional de Desaparecidos, se hace más remota. Las personas que reconocen los hechos asociados a las desapariciones, en su mayoría familiares, con el paso de los años pueden perder detalles valiosos o pudieron haber estado o aún estar sometidos a amenazas que les haya impedido denunciar su caso; haber sido sometidos a la misma u otro tipo de violencias como persecuciones, desplazamiento forzado, asesinatos por

4 Datos extraídos del Registro Nacional de Desaparecidos (RND).

5 Registro Nacional de Desaparecidos (RND), reglamentado solo hasta el año 2005, por el Decreto Nacional 4218. Es un sistema técnico, conformado por diferentes plataformas tecnológicas, las cuales recogen, almacenan, administran, gestionan y presentan información sobre personas desaparecidas y cadáveres en condición de no identificados. Este sistema es gestionado por diferentes entidades estatales intervinientes como lo define la Ley 589 de 2000. Dentro del RND, se encuentra el Sistema de Información Red de Desaparecidos y Cadáveres (SIRDEC), en el cual se registran de manera permanente a partir del año 2007, reportes de personas desaparecidas e información de cadáveres sometidos a necropsia médico legal; así mismo, los casos retrospectivos a dicha fecha. Esta información se administra en módulos: módulo de desaparecidos y módulo de cadáveres, los cuales permiten su comparación en lo que se denomina "cruce técnico o referencial de información". Cuando las coincidencias entre características son altas, puede orientarse la identificación de un cuerpo; sin embargo, lograrlo es un proceso complejo pues existe dependencia de la cantidad y del estado de la información antemortem y postmortem contenida tanto en el módulo de desaparecidos como en el de cadáveres.

6 Mecanismo de Búsqueda Urgente (MBU), reglamentado solo hasta 2005 por la ley 971. 
atreverse a preguntar por lo sucedido; asesinato de otros familiares, o simplemente haber muerto por razones diferentes al conflicto y con ello la posibilidad de denuncia y registro de información.

Es fundamental reconocer que las cifras por si solas jamás permitirán un acercamiento a la profundidad del fenómeno, entendida esta como todas las multiplicidades que definen su drama en el tiempo y en el espacio. No obstante, no se puede desconocer que para el investigador sí plantean un punto de partida importante y potencial sobre el cual desglosar sus análisis y posteriormente consolidar sus conclusiones, allí los análisis geográficos son fundamentales. Particularmente, para los fines de la investigación en la que se suscribe el presente artículo, la revisión de los datos significó reconocer diferentes dificultades en ellos, evidenciando un vacío de información relevante; por esto mismo, implicó hacer una exhaustiva verificación de la población objetivo.

Se partió de una población total inicial de 487 casos de personas desparecidas aparecidas muertas, las registradas para el departamento de Antioquia, en una temporalidad inicial entre 1980 y 2015 . Dicha población tuvo una primera revisión según el número de casos por municipio de desaparición, tomándose metodológicamente aquellos municipios que presentaban por encima de los cinco casos, con excepción del municipio antioqueño de Amalfi, cuyos cuatro casos presentaron información suficiente para ser incluido en el estudio, quedando un total de 327 casos (Tabla 1 ).

Definida esta población por municipio, se siguió con una revisión caso por caso para verificar en estos, la información disponible y su estado según las categorías de interés. Se observó que la mayoría de los casos no estaba asociada con un cadáver directamente, pues solo 36 de estos contaban con esta información necesaria para verificar el estado mortal del desparecido, así como para determinar las variables temporales y espaciales del estado de la aparición. Partiendo de este panorama se decidió indagar las variables de interés, revisando los campos de información textual: "Breve descripción de los hechos" y "Seguimiento del caso", 7 en cada uno de los registros.

La información revisada en los campos mencionados, a su vez, mostró nuevas situaciones que llevaron a delimitar aún más la población, por ejemplo, de los 327 registros revisados, en una gran parte no se encontró información sobre momento y lugar de hallazgo de la persona desaparecida, por lo tanto, fueron excluidos. En otros casos se pudo establecer que no se trataba de desapariciones, sino de asesinatos directos mencionados en los relatos y que, para el contexto del conflicto en ese momento, los familiares debían enterrar a sus seres queridos en 
Tabla 1. Desaparecidos aparecidos muertos por municipio. Antioquia 1980-2015

\begin{tabular}{lc} 
Población de desaparecidos en & $\begin{array}{c}\text { Antioquia por encima de los cinco casos, por } \\
\text { municipio }\end{array}$ \\
\hline Amalfi & 4 \\
Anorí & 5 \\
Argelia & 7 \\
Briceño & 7 \\
Campamento & 6 \\
Carepa & 10 \\
Chigorodó & 6 \\
Dabeiba & 19 \\
El Carmen De Viboral & 11 \\
Frontino & 9 \\
Granada & 24 \\
Ituango & 34 \\
La Ceja & 5 \\
Mutatá & 9 \\
Nariño & 14 \\
Necoclí & 13 \\
Puerto Berrío & 6 \\
San Carlos & 34 \\
San Luis & 9 \\
Sonsón & 8 \\
Sopetrán & 8 \\
Tarazá & 8 \\
Turbo & 63 \\
Urrao & 327 \\
Total general & \\
\hline & \\
\hline
\end{tabular}

Fuente: SIRDEC/RND. Elaboración propia a partir de Cifuentes, 2020.

las mismas fincas o en los cementerios locales, sin posibilidad de legalizar sus muertes, estos casos también se excluyeron. Finalmente, a través de este proceso se llegó a una población de 113 casos de personas desaparecidas aparecidas muertas (Tabla 2). Plantear estas aclaraciones metodológicas es fundamental para comprender la complejidad de este tipo de análisis en relación al uso cuidadoso de sus fuentes para evitar conclusiones equívocas (Avendaño, 2011).

Llegar a esta población final, da cuenta de los retos que plantea la información disponible, pues los vacíos no son pocos. Un ejemplo concreto se puede ver en la proporción entre las cifras generales de personas desaparecidas en el departamento de Antioquia entre los años 1980 y 2015 entregadas por las diversas 
Tabla 2. Población desaparecidos aparecidos muertos.

Antioquia 1993-2016

\begin{tabular}{clc}
\hline \multicolumn{3}{c}{ Población desaparecidos aparecidos muertos por } \\
Municipio de desaparición \\
\hline 1. & Amalfi & 4 \\
2. & Argelia & 3 \\
3. & Briceño & 3 \\
4. & Campamento & 1 \\
5. & Chigorodó & 3 \\
6. & Dabeiba & 2 \\
7. & El Carmen de Viboral & 6 \\
8. & Frontino & 2 \\
9. & Granada & 9 \\
10. & Ituango & 11 \\
11. & La Ceja & 5 \\
12. & Mutatá & 4 \\
13. & Nariño & 4 \\
14. & Puerto Berrío & 2 \\
15. & San Carlos & 21 \\
16. & San Luis & 5 \\
17. & San Pedro de Urabá & 2 \\
18. & Sonsón & 3 \\
19. & Sopetrán & 8 \\
20. & Turbo & 11 \\
21. & Urrao & 4 \\
\hline & & 113 \\
\hline & & Total general \\
\hline
\end{tabular}

Fuente: $\quad$ SIRDEC/RND/INMLCF. Elaboración propia a partir de Cifuentes, 2020.

autoridades e informes, en relación con la cifra de población final depurada y delimitada para el estudio (Figura 1).

De igual manera, esta revisión y depuración de los datos conllevó a una delimitación temporal, pasando del periodo inicial mencionado (1980 a 2015) a un periodo final, donde las desapariciones de las 113 personas caracterizadas en los 21 municipios antioqueños, sucedieron desde 1993 y sus posteriores hallazgos se dieron hasta 2016 (Figura 2). Esta fue la base para ratificar igualmente la delimitación espacial, reiterando que es necesario realizar este tipo de estudios en más áreas del país, acorde con las particularidades.

De las 113 personas desaparecidas aparecidas muertas el 87.6\% correspondió a población masculina y el $12.38 \%$ a población femenina (Figura 3). Ello mantiene la concordancia tal como se ha expuesto en diferentes informes sobre derechos humanos o relacionados con el conflicto armado colombiano, en los cuales se ha indicado que las principales víctimas de la materialidad de la desaparición 


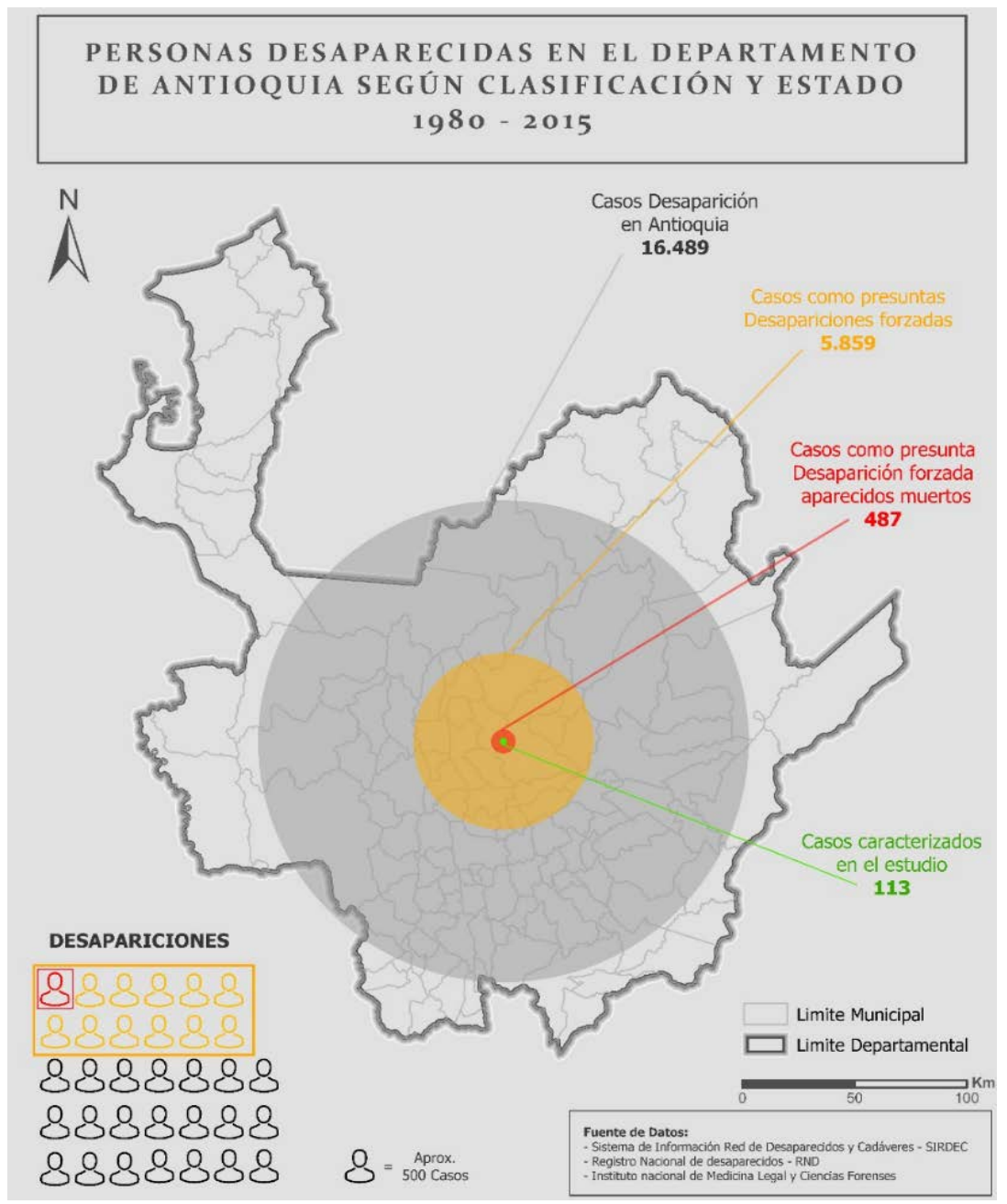

Figura 1. Proporción en las cifras sobre personas desaparecidas en el departamento de Antioquia vs la cifra de la población depurada objeto de análisis. Elaboración propia a partir de Cifuentes (2020).

forzada son hombres (CNMH, 2016 y Observatorio de Derechos Humanos y Derecho Humanitario, 2012). Esta proporción cambia directamente de manera inversa cuando se analiza el carácter de continuidad de esta violencia. Por ejemplo, al observar la desaparición una vez es ejecutada, se ve de manera clara como las mujeres son mayoritariamente víctimas, pues son a ellas, principalmente madres, esposas o compañeras sentimentales, hermanas e hijas a 


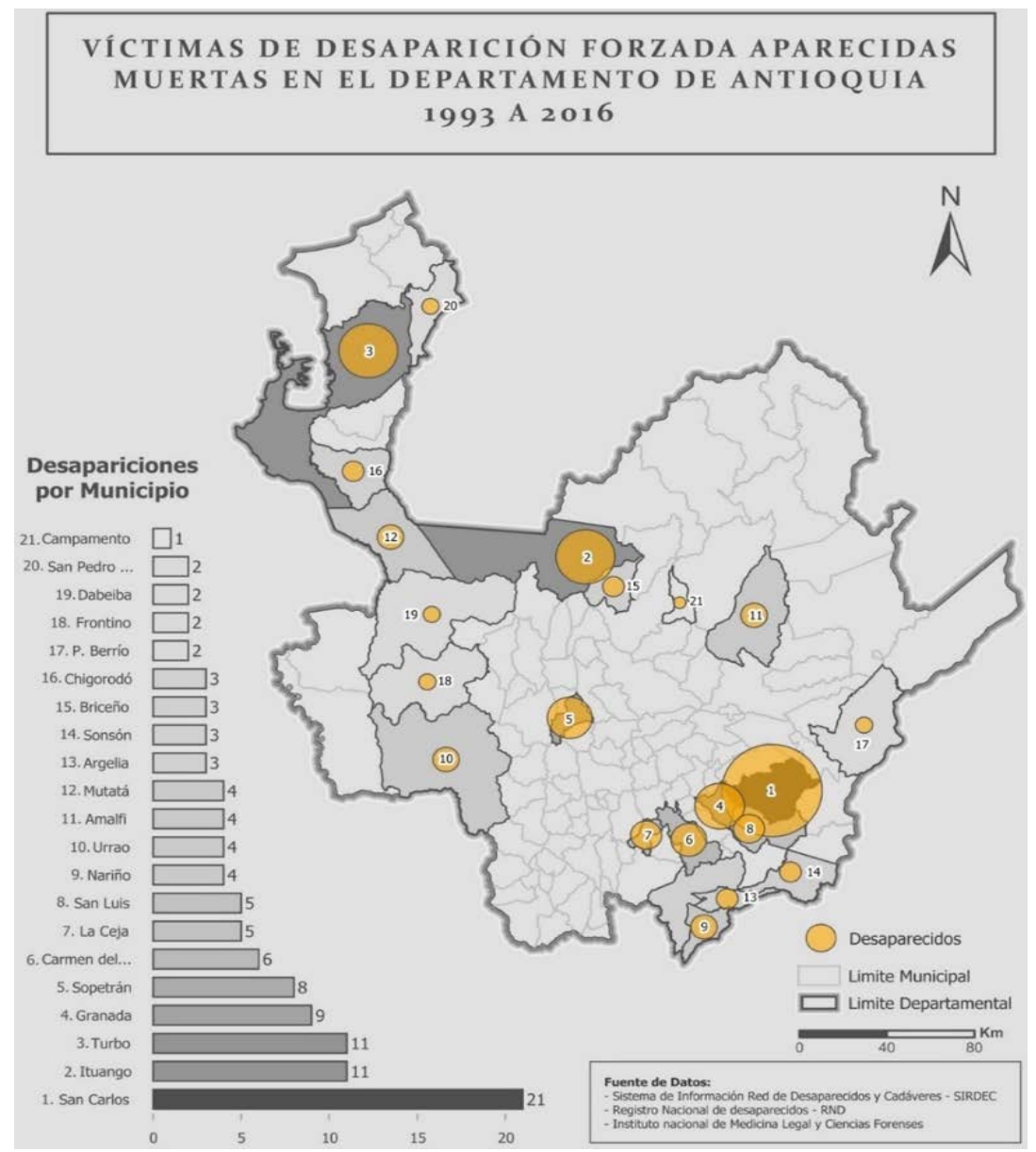

Figura 2. Población de víctimas de desaparición forzada aparecidas muertas, caracterizada en el departamento de Antioquia, entre 1993 y 2016. Elaboración propia a partir de Cifuentes (2020).

quienes se desplaza esta violencia en sus impactos morales, económicos, psicológicos, de seguridad y estabilidad, entre otros (Cifuentes y Ramírez, 2014). En este sentido, se puede decir que las mujeres que sufren esta violencia, se hacen acreedoras en una victimización en doble vía (Cifuentes y Ramírez, 2014).

Al revisar ambas poblaciones por rangos de edad (Figura 4 y Figura 5) al momento de la desaparición, se observa que la mayoría de personas se ubican en el rango de 25 a 29 años, tanto mujeres como hombres; seguido del rango entre 50 a 54 años para mujeres, mientras que para hombres el rango seguido está 


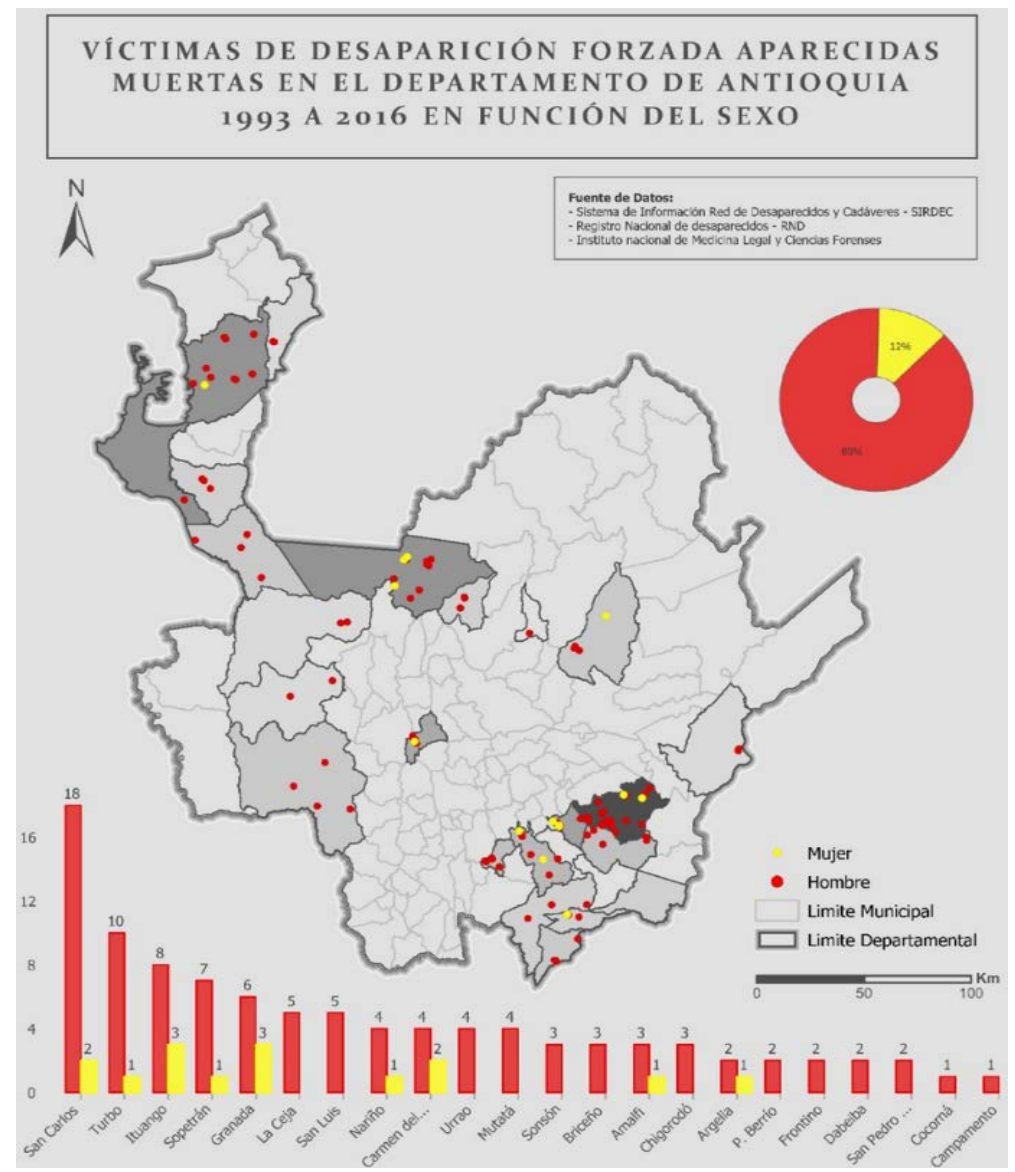

Figura 3. Personas desaparecidas aparecidas muertas, de acuerdo al sexo. En el departamento de Antioquia, entre 1993 y 2016. Elaboración propia a partir de Cifuentes (2020).

entre los 40 y 44 años. Aunque la mayoría de las personas desaparecidas, tanto hombres como mujeres, están concentrados en rangos de edad adulta, se observa que este tipo de violencia en un escenario de conflicto también ha sido perpetrado en niños, adolescentes, jóvenes y adultos mayores.

Es conocido que las víctimas distintivas en la práctica de la desaparición forzada dentro del conflicto eran pobladores locales de los lugares en los cuales se desarrolla el hecho (CNMH, 2016); aspecto que se corrobora en los datos, en tanto las principales víctimas de esta acción, en las diferentes regiones de Antioquia, fueron pobladores campesinos que habitaban en el área de influencia en donde se notifica la desaparición (Figura 6). 


\begin{tabular}{|c|c|c|c|c|c|c|c|}
\hline \multirow{4}{*}{$\begin{array}{r}\mathrm{R} \\
(15 \mathrm{a} 17)\end{array}$} & \multicolumn{7}{|c|}{ Rango de edad en mujeres al momento de la desaparición. } \\
\hline & & & & & & & \\
\hline & ) & 1 & 2 & & 3 & 4 & 5 \\
\hline & $\begin{array}{c}(15 \mathrm{a} \\
17)\end{array}$ & $\begin{array}{c}(20 a \\
24)\end{array}$ & $\begin{array}{c}(25 \mathrm{a} \\
29)\end{array}$ & $\begin{array}{c}(30 \mathrm{a} \\
34)\end{array}$ & $\begin{array}{c}(40 \mathrm{a} \\
44)\end{array}$ & $\begin{array}{c}(50 \mathrm{a} \\
54)\end{array}$ & $\begin{array}{c}(55 \mathrm{a} \\
59)\end{array}$ \\
\hline 口 Total & 2 & 1 & 4 & 2 & 1 & 3 & 1 \\
\hline
\end{tabular}

Figura 4. Rango de edad en mujeres desaparecidas aparecidas muertas. Antioquia 19932016.

Fuente: SIRDEC/RND/INMLCF. Elaboración propia a partir de Cifuentes (2020).

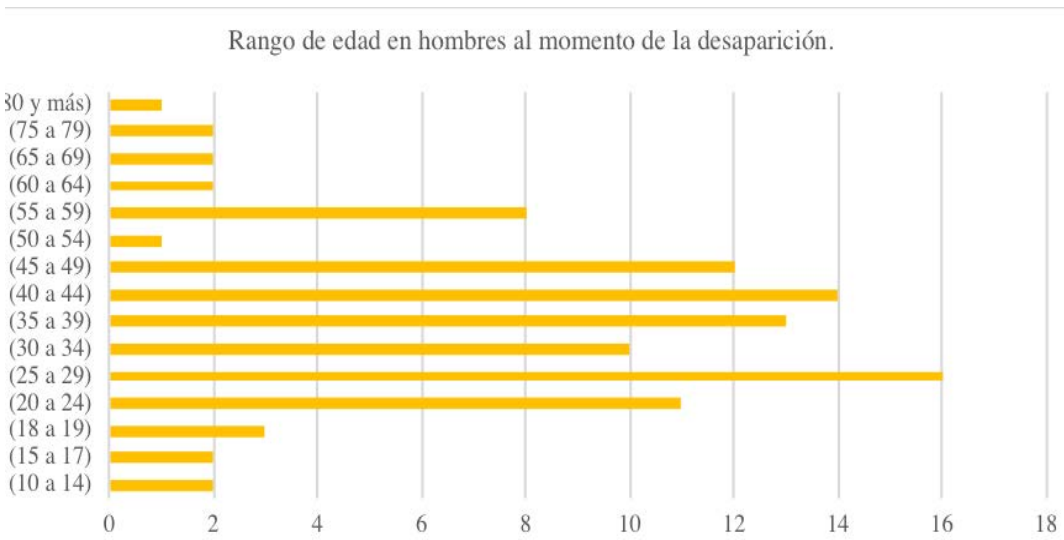

Figura 5. Rango de edad en hombres desaparecidos aparecidos muertos. Antioquia 1993-2016.

Fuente: SIRDEC/RND/INMLCF. Elaboración propia a partir de Cifuentes (2020).

Categorías según ocupación

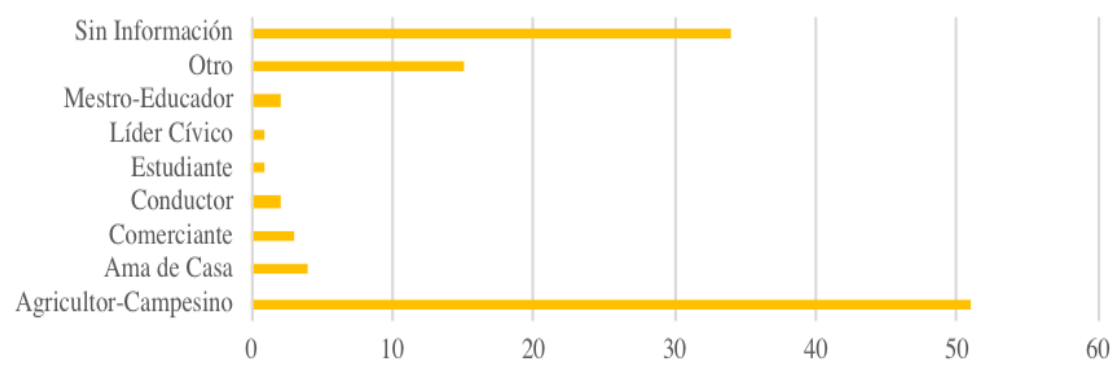

Figura 6. Categorías según ocupación de personas desaparecidas aparecidas muertas. Antioquia 1993 a 2016.

Fuente: SIRDEC/RND/INMLCF. Elaboración propia a partir de Cifuentes (2020). 
Movimientos espaciales y temporalidades de la materialidad de la desaparición forzada en Antioquia. Análisis multiescalar y singular

La población de personas desaparecidas aparecidas muertas del departamento de Antioquia, caracterizada en función de su desaparición, y que se distribuyó en los 21 municipios mencionados, se concentró en siete de sus nueve subregiones: Magdalena Medio, Nordeste, Norte, Occidente, Oriente, Suroeste y Urabá (Figura 7).

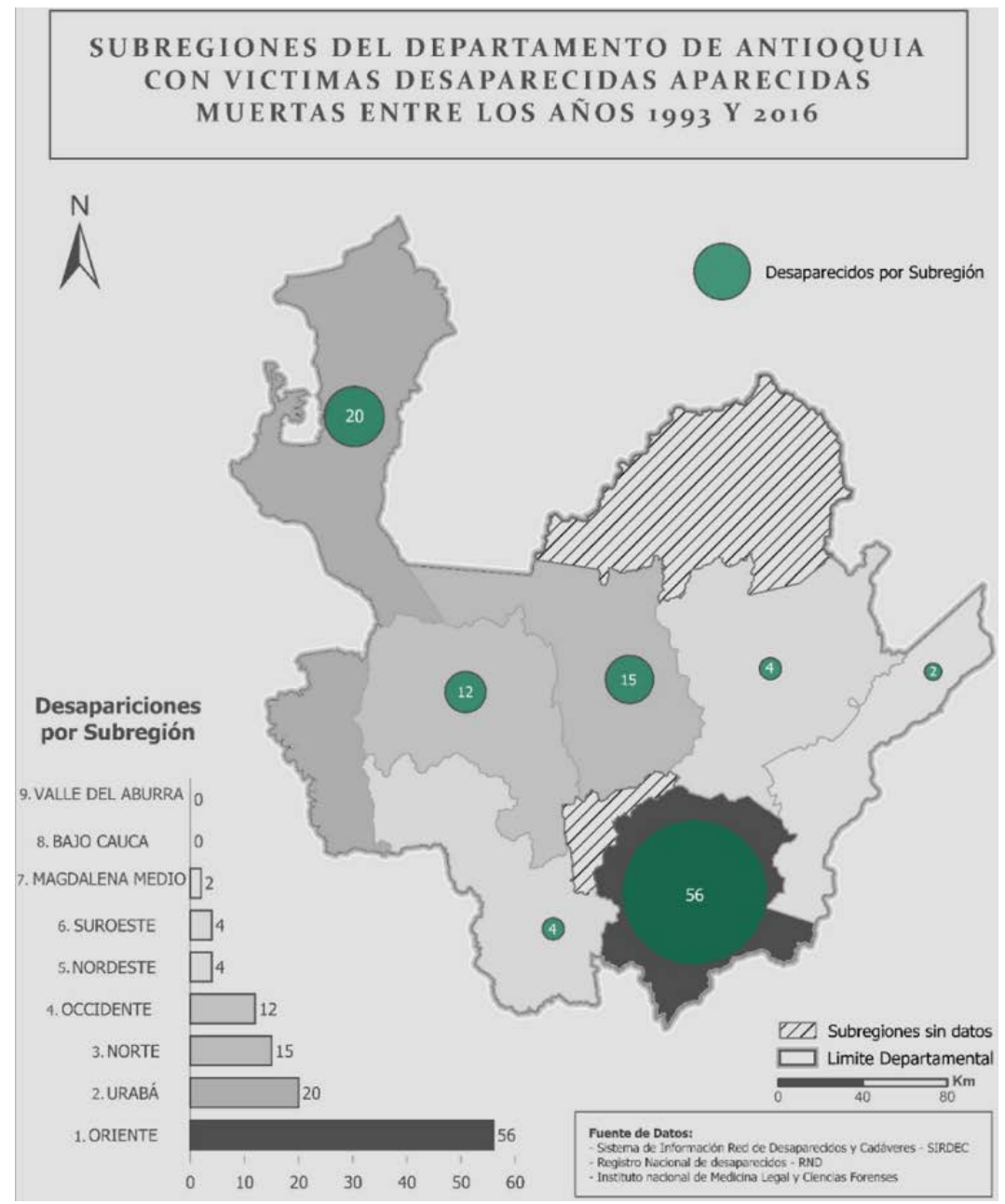

Figura 7. Personas desaparecidas aparecidas muertas por subregión de Antioquia. Entre 1993 y 2016. Elaboración propia a partir de Cifuentes (2020). 
Tabla 3. Desaparecidos según municipio y departamento de hallazgo

\begin{tabular}{|c|c|c|c|c|c|c|c|}
\hline \multirow{2}{*}{$\begin{array}{c}\text { Municipio } \\
\text { de } \\
\text { hallazgo }\end{array}$} & \multicolumn{7}{|c|}{ Departamentos de hallazgo } \\
\hline & Antioquia & Caquetá & Cesar & Chocó & Córdoba & $\begin{array}{l}\text { Norte de } \\
\text { Santander }\end{array}$ & $\begin{array}{c}\text { Total } \\
\text { de } \\
\text { casos }\end{array}$ \\
\hline Amalfi & 4 & - & - & - & - & - & 4 \\
\hline Argelia & 2 & - & - & - & - & - & 2 \\
\hline $\begin{array}{l}\text { Belén de Los } \\
\text { Andaquíes }\end{array}$ & - & 1 & - & - & - & - & 1 \\
\hline Briceño & 4 & - & - & - & - & - & 4 \\
\hline Chigorodó & 2 & - & - & - & - & - & 2 \\
\hline Cocorná & 4 & - & - & - & - & - & 4 \\
\hline $\begin{array}{l}\text { El Carmen } \\
\text { de Viboral }\end{array}$ & 4 & - & - & - & - & - & 4 \\
\hline Granada & 4 & - & - & - & - & - & 4 \\
\hline Ituango & 10 & - & - & - & - & - & 10 \\
\hline La Ceja & 5 & - & - & - & - & - & 5 \\
\hline La Unión & 1 & - & - & - & - & - & 1 \\
\hline Nariño & 4 & - & - & - & - & - & 4 \\
\hline Olaya & 1 & - & - & - & - & - & 1 \\
\hline Pelaya & - & - & 1 & - & - & - & 1 \\
\hline Rionegro & 1 & - & & - & - & - & 1 \\
\hline Riosucio & & - & - & 4 & - & - & 4 \\
\hline San Carlos & 22 & - & - & & - & - & 22 \\
\hline San Luis & 5 & - & - & - & - & - & 5 \\
\hline $\begin{array}{l}\text { San Pedro } \\
\text { de Urabá }\end{array}$ & 1 & - & - & - & - & - & 1 \\
\hline San Roque & 1 & - & - & - & - & - & 1 \\
\hline Sonsón & 5 & - & - & - & - & - & 5 \\
\hline Sopetrán & 8 & - & - & - & - & - & 8 \\
\hline Tibú & - & - & - & - & & 1 & 1 \\
\hline Tierra Alta & - & - & - & - & 1 & - & 1 \\
\hline Turbo & 13 & - & - & - & - & - & 13 \\
\hline Urrao & 4 & - & - & - & - & - & 4 \\
\hline Total de casos & 105 & 1 & 1 & 4 & 1 & 1 & 113 \\
\hline
\end{tabular}

Fuente: $\quad$ SIRDEC/RND/INMLCF. Elaboración propia a partir de Cifuentes (2020). 
Con excepción de la subregión del Bajo Cauca por falta de información y el Valle de Aburra, excluida metodológicamente de la delimitación espacial por tratarse del área metropolitana, cuyas dinámicas urbanas de conflicto y criminalidad ameritan una investigación propia que las analice. En este sentido se recomienda revisar el caso de otros centros urbanos en el país, por ejemplo, el conglomerado urbano en el que se ubica Bogotá (Avendaño, 2011), en donde la conurbación presentó hechos del mismo delito.

Al iniciar con la revisión de la población, pero esta vez en función del lugar de hallazgo, se presentó una variación espacial de acuerdo con la distribución de los cuerpos hallados en municipios por fuera del departamento de Antioquia (Tabla 3), es decir, que vivos o muertos fueron transportados a lugares lejanos de su familia, con el fin de ampliar la revictimización y exponenciar la dificultad de hallazgo final. Esta fue la situación de ocho8 de los 113 casos analizados.

Con respecto a la temporalidad en la materialidad de la desaparición forzada, se pueden diferenciar dos periodos: el primero en función del momento de la desaparición dado entre 1993 y 2012; y uno segundo sin sucesos en los años 2006, 2007 y 2008 (Figura 8).

A su vez, en esta temporalidad se diferencian tres submomentos: el primero, que evidencia un aumento del número de desapariciones caracterizadas a partir de 1994, que desciende en 1998 (Figura 8). Espacialmente estos casos pertenecen mayoritariamente a municipios de la subregión del Urabá (Turbo, San Pedro de Urabá, Mutatá y Chigorodó), seguido por las subregiones del Occidente, Oriente y un bajo número de la subregión Occidente.

Un segundo momento, entre 2000 y 2005 (Figura 8), en el que se concentró el mayor número de desapariciones caracterizadas, las cuales correspondieron espacialmente, en su mayoría, a la región del Oriente, siendo predominante las desapariciones en el municipio de San Carlos. Es decir, en esta temporalidad se evidencia el "desplazamiento" del fenómeno a otras regiones por su condición geoestratégica y la intensificación del conflicto armado por parte de otros actores (Cifuentes, 2020). Finalmente, un tercer momento marcado particularmente por ocho desapariciones en el año 2011 (Figura 8), todas correspondientes al municipio de Sopetrán del Occidente Antioqueño.

El Centro Nacional de Memoria Histórica (2016), dentro de su investigación sobre la desaparición forzada, establece una cronología en la tendencia histórica de esta violencia en el país, representado en el gráfico de la Figura 9.

Dentro de la explicación, allí se mencionan diferentes periodos y categorizaciones:

- 1970 a 1981, en el cual la desaparición forzada registró bajos niveles de ocurrencia, pero con un tránsito de la marginalidad -hasta 1977- a la 


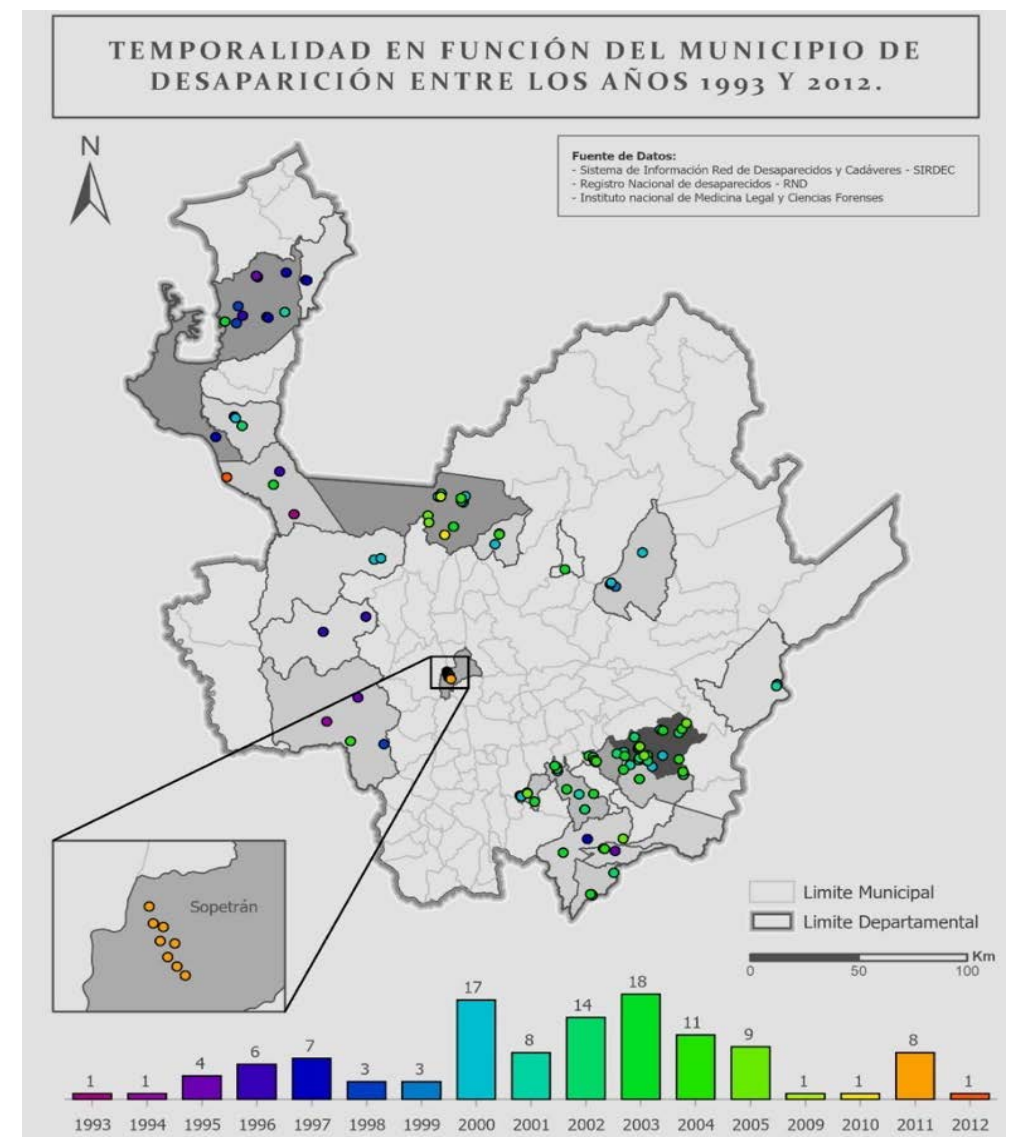

Figura 8. Temporalidad según el municipio de la desaparición. Entre 1993 y 2012. Elaboración propia a partir de Cifuentes (2020).

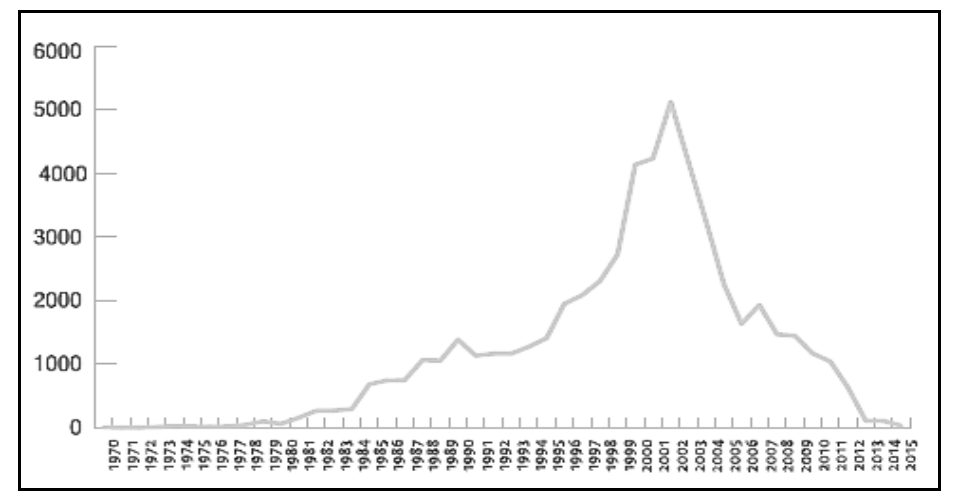

Figura 9. Tendencia de la desaparición forzada.

Fuente: CNMH (2016). 
regularidad -hasta 1981-. Se pasa de un promedio de una desaparición por mes -entre 1970 a 1977- a una cada cuatro días -entre 1978 a 1981-; registrándose un total de 485 víctimas.

- 1982 a 1990, en este periodo se da una tendencia de tránsito de la regularidad a la generalización. Observándose una prevalencia en el crecimiento continuo. De 485 víctimas dadas en el periodo anterior, pasa a 6528 registros en este periodo. La tendencia de las desapariciones ya no es por días, sino por horas.

- 1991 a 1995, en este periodo, la tendencia se expresa en un decrecimiento moderado con aparente estabilidad. No indica un aumento, ni presenta un declive significativo, pasando de 6528 casos a 6 155, mostrando más que una disminución, una contención en la ocurrencia del fenómeno; sin embargo, se muestra un punto crítico en 1995.

- 1996 a 2005, en este periodo, se muestra un tránsito de la contención a la explosión, con una tendencia de crecimiento acelerada, pasando a 32249 desapariciones, las que en promedio equivaldrían a una desaparición forzada cada dos horas y media.

- 2006 a 2015, en este último periodo, se observa un tránsito de la explosión del fenómeno al declive, con un pico de crecimiento en 2007.

De acuerdo con la anterior periodización del fenómeno y revisando la temporalidad de las desapariciones caracterizada en el presente análisis (Figura 9), podría decirse que esta se ubica en una tendencia general dentro del rango de crecimiento y declive histórico, específicamente entre el límite superior del periodo entre 1991 y 1995 y el límite superior del periodo entre 1996 a 2005. Es decir, se observa un incremento continuo de los casos a partir de 1995 hasta 1997 y de allí un decrecimiento que nuevamente aumenta en 2000, ubicándose principalmente en la categoría de explosión y crecimiento acelerado de las desapariciones históricas presentada por Memoria Histórica.

El segundo periodo que se puede reconocer en la materialidad de la desaparición forzada está dado en función al momento de hallazgo, entre 2001 y 2016, sin hallazgos caracterizados en 2002, 2004, 2006 y 2015 (Figura 10). Esta temporalidad muestra un momento principal, comprendido entre 2007 y 2011, en el cual se concentra la mayoría de hallazgos de los cuerpos de las personas desaparecidas caracterizadas, tendencia principalmente marcada en 2007 (Figura 10).

Se observa que los hallazgos concentrados en el año 2007, se distribuyeron en diferentes municipios, cubriendo casi todas las subregiones caracterizadas (Urabá, Oriente, Norte, Nordeste y Occidente), mientras que los hallazgos concentrados entre 2009 y 2011, se reflejan en su mayoría en los municipios del Oriente antioqueño, seguido por el municipio de Ituango de la subregión Norte y en el municipio de Turbo de la subregión de Urabá (Cifuentes, 2020). Lo anterior 


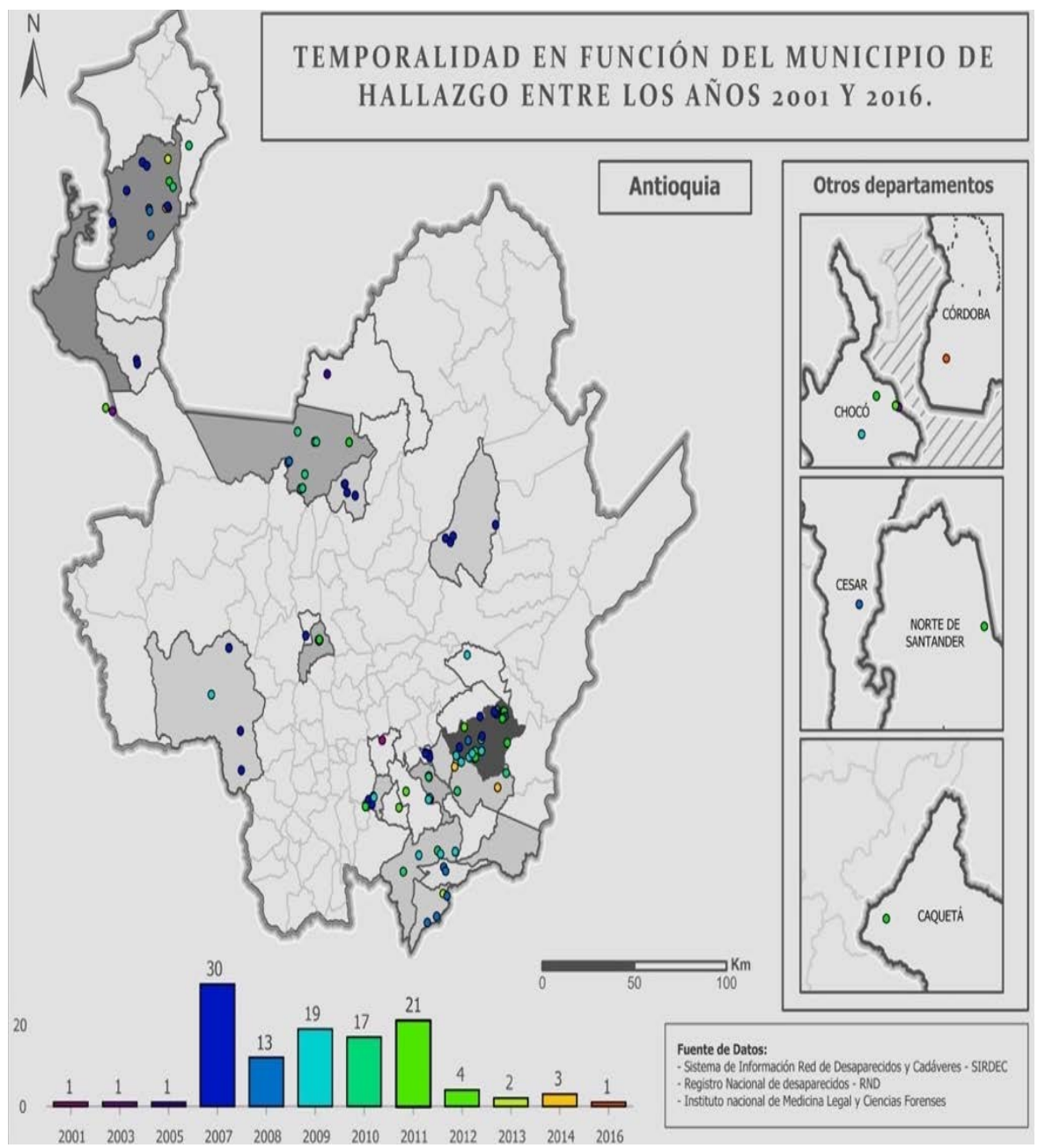

Figura 10. Temporalidad según el municipio de hallazgo. Entre 2001 y 2016. Elaboración propia a partir de Cifuentes (2020).

tiene que ver con las maneras victimizantes que unos y otros grupos armados ejercían, su presencia y control territorial, dicho de otra manera, la concentración o dispersión de cuerpos en fosas habla de las modalidades y el ejercicio de poder en la región.

De igual manera, llama la atención la tendencia casi secuencial expresada entre la temporalidad de las desapariciones y la temporalidad de los hallazgos; es decir, se refleja cómo el número de las desapariciones caracterizadas empieza adecrecer en 2005 y casi dos años después, en 2007, se refleja el mayor número 
decuerpos hallados, tendencia que puede explicarse en la actividad que presentó la Unidad de Justicia y Paz de la Fiscalía General de la Nación, particularmente en la operatividad en las diligencias de exhumación, que para 2007 fue notoria (Figura 11).

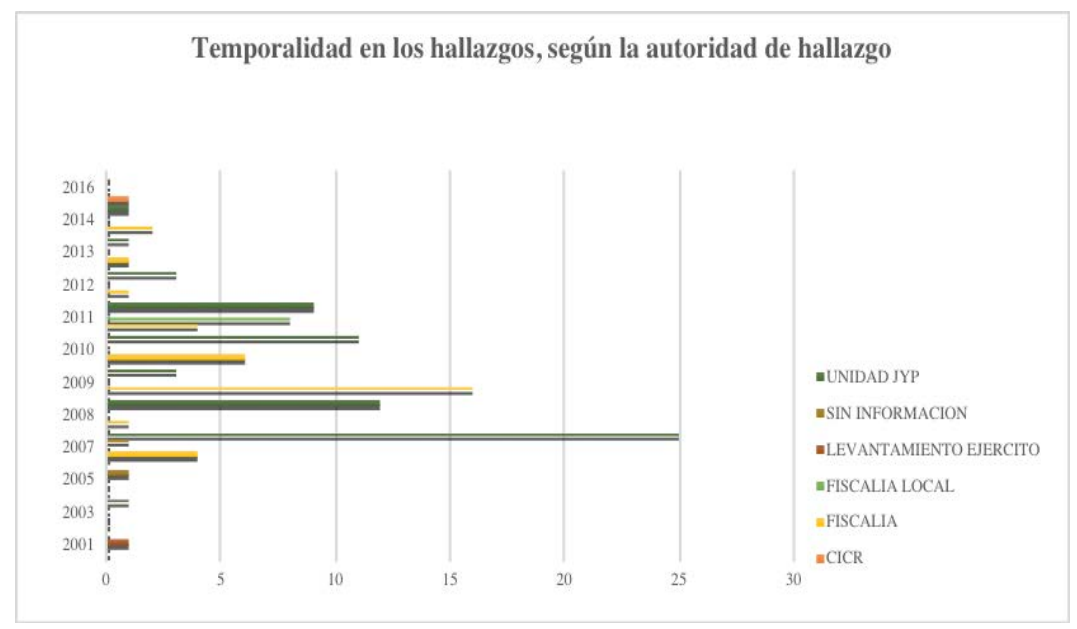

Figura 11. Temporalidad de los hallazgos, de acuerdo con la autoridad que recupera los cuerpos, entre 2001 y 2016.

Fuente: SIRDEC/RND/INMLCF. Elaboración propia a partir de Cifuentes (2020).

La dinámica de las desapariciones forzadas sucedidas en estos 21 municipios y los posteriores hallazgos de sus cuerpos, mostraron una espacialidad multiescalar, dinamizada en parte por movimientos en flujos y trayectorias en los que se evidenciaron flujos interdepartamentales, definidos a partir de las desapariciones sucedidas en municipios de Antioquia hasta el hallazgo de los cuerpos en municipios de otros departamentos. De igual manera, se observaron flujos intermunicipales, establecidos por desapariciones dadas en unos municipios, cuyos cuerpos fueron hallados en municipios diferentes, dentro del departamento de Antioquia. Por otro lado, se presentó una marcada tendencia de las desapariciones con cadáveres encontrados en el mismo municipio, dentro de este grupo pueden verse en algunos casos, movimientos en flujo interveredales, con desaparición y hallazgos en veredas diferentes; asimismo, en otros casos una dinámica puntual a escala veredal, caracterizada por desapariciones y hallazgos en las mismas veredas. Estas excepcionalidades geográficas abren una nueva línea escalar de reflexión. 


\section{Flujos Interdepartamentales}

Estos movimientos están dados por el 7\% de los casos caracterizados; es decir, ocho cuerpos de los 113 desaparecidos en diferentes municipios de Antioquia se hallaron en municipios de otros departamentos. Es así como, de las dos desapariciones caracterizadas en Puerto Berrio, uno de los cuerpos fue hallado en el municipio de Pelaya, Cesar y el otro en Belén de los Andaquíes, en el departamento del Caquetá. De igual manera, una de las once personas desaparecidas en el municipio de Ituango, su cuerpo se encontró en Tibú, Santander. Tres de las personas desparecidas en el municipio de Mutatá, sus cuerpos fueron encontrados, uno en Tierra Alta, departamento de Córdoba y dos en el municipio de Riosucio, Chocó; en este último, también fueron hallados dos cuerpos, correspondientes con una persona desaparecida en el municipio Chigorodó y con otra persona desaparecida en el municipio de Dabeiba (Figura 12).

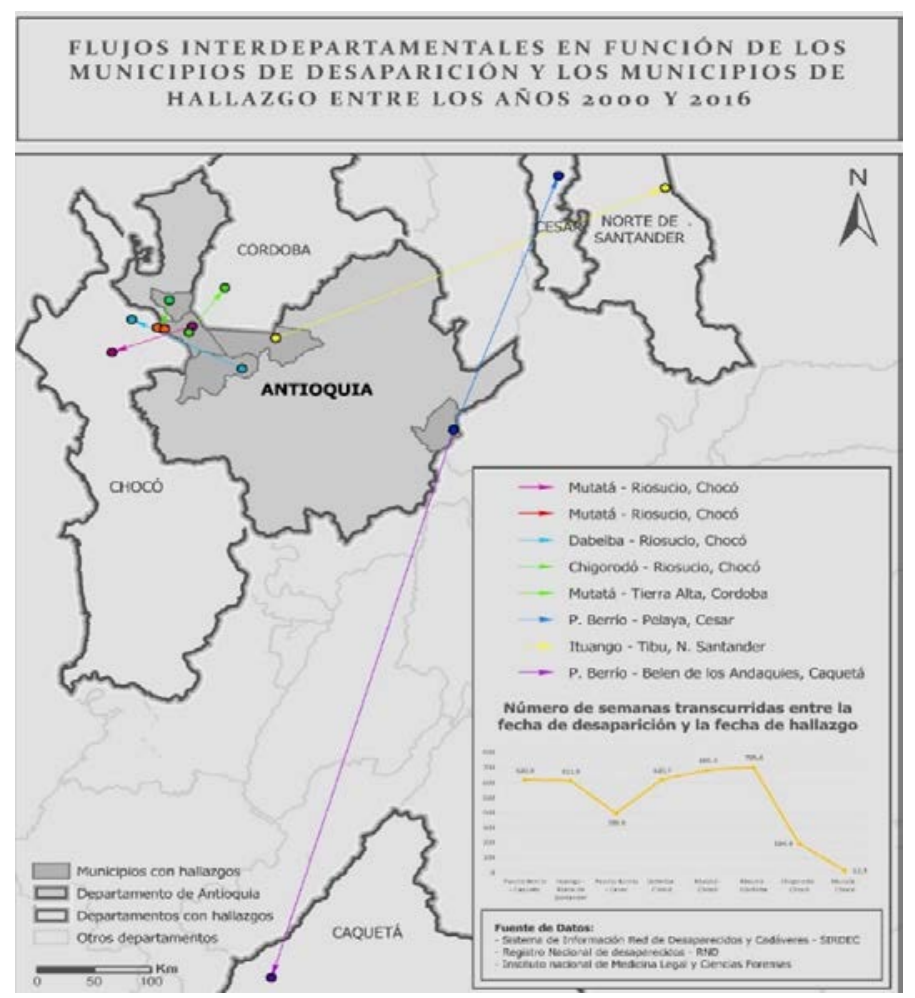

Figura 12. Flujos interdepartamentales. Trayectos desde municipio de desaparición del departamento de Antioquia hasta los municipios de hallazgo en otros departamentos, entre 1993 y 2011. Elaboración propia a partir de Cifuentes (2020). 
Estos trayectos dibujados por estos ocho acontecimientos de desapariciones y posteriores hallazgos de sus víctimas mortales, plantean situaciones diferenciales y una compleja multiplicidad en el contexto espacial y temporal en la materialidad de esta violencia. Por ejemplo, la persona desaparecida en el municipio de Ituango, correspondió a una mujer de 22 años, quien fue interceptada por miembros de las Autodefensas Unidas de Colombia (AUC), ${ }^{8}$ cuando se desplazaba en transporte público, según su familiar reportante, cuando se dirigió a este grupo a preguntar por el paradero de su hija, dijeron que un comandante la requería, fue lo último que supo de ella, once años más tarde (Tabla 4) su cuerpo fue hallado en el municipio de Tibú, Norte de Santander, dejando vacíos en los flujos espaciales posibles desde el lugar de desaparición al lugar donde su cuerpo fue encontrado inhumado a más 500 kilómetros de la desaparición.

Quienes desaparecieron en el municipio de Mutatá, correspondieron con tres hombres de edades adultas, entre los 50 y 84 años. Uno de ellos se encontraba en su casa cuando llegaron hombres uniformados y armados, fue amarrado, su casa incinerada y su cuerpo fue hallado trece años después (Tabla 4) en Riosucio, Chocó. El segundo hombre corresponde a un líder reclamante de tierras, miembro del Comité de Censo del Consejo Comunitario de Curvaradó, quien fue interceptado con su hijo por paramilitares de las Autodefensas Gaitanistas de Colombia (AGC) ${ }^{9}$ en 2012, cuando se desplazaban en transporte público de Mutatá a Curvaradó, previamente a la intercepción y rapto por los hombres de este grupo, fueron retenidos y señalados como guerrilleros por miembros efectivos de la policía; la desaparición de esta persona fue denunciada por la Comisión Intereclecial de Justicia y Paz ante la Procuraduría General de la nación, donde a pesar de las acciones por parte de organizaciones sociales y de derechos humanos e instituciones como el Instituto Nacional de Medicina Legal y Ciencias Forenses (INMLCF) y la Comisión de Búsqueda de Personas Desaparecidas, a través de la activación del Mecanismo de Búsqueda Urgente.

Infortunadamente no se logró el hallazgo con vida de la persona desaparecida, pues su cuerpo fue recuperado en Riosucio, Chocó en el mismo año (Tabla 4), cinco días después de su desaparición, por diligencias entre el INMLCF y miembros del Cuerpo Técnico Investigativo (CTI) de la Fiscalía General de la Nación. El tercer hombre desaparecido en el municipio de Mutatá, corresponde con un adulto mayor de 84 años, quien fue raptado de su finca en 2003, por hombres del frente 5 de las Fuerzas Armadas Revolucionarias de Colombia

Autodefensas Unidas de Colombia corresponde a estructura paramilitar que operaba allí

Autodefensas Gaitanistas de Colombia, corresponde con una estructura paramilitar que operaba en la zona, en el escenario de reconfiguración de estos grupos en el rearme y control territorial sucedida posterior a la ‘desmovilización' en el año 2005 con la Ley de Justicia y Paz. 
(FARC-EP), ${ }^{10}$ quien estuvo en cautiverio con una afección cardiaca, su cuerpo fue hallado en Tierra Alta, Córdoba en el Nudo de Paramillo, trece años posterior a su desaparición en el año 2016 (Tabla 4). El hallazgo de su cuerpo se da por la acción del Comité Internacional de la Cruz Roja (CICR), en el marco de la aplicación de acciones de búsqueda humanitaria planteadas en el Comunicado Conjunto No. 62 del 17 de octubre de 2015, expedido desde la "mesa de negociaciones para la terminación del conflicto y la construcción de una paz estable y duradera en Colombia". Las dos personas desaparecidas en los municipios de Chigorodó y Dabeiba, correspondieron con dos hombres quienes se desplazaban juntos en un camión y que fueron interceptados por hombres armados, cuyos cuerpos fueron hallados en una misma fosa en Riosucio, Chocó, once años después (Tabla 4), por información del postulado alias “El ruso", en los escenarios de verdad y justicia territorial de Ley de Justicia y Paz.

Tabla 4. Municipios de desaparición y hallazgo, a partir de los cuales se construyen los flujos interdepartamentales y sus temporalidades

\begin{tabular}{llcc}
\hline $\begin{array}{c}\text { Municipio de } \\
\text { desaparición }\end{array}$ & \multicolumn{1}{c}{$\begin{array}{c}\text { Municipio/ } \\
\text { Departamento de hallazgo }\end{array}$} & $\begin{array}{c}\text { Año de } \\
\text { desaparición }\end{array}$ & $\begin{array}{c}\text { Año de } \\
\text { hallazgo }\end{array}$ \\
\hline Puerto Berrio & Pelaya/César & 2001 & 2008 \\
& $\begin{array}{l}\text { Belén de los } \\
\text { Adaquíes/Caquetá }\end{array}$ & 2000 & 2011 \\
Ituango & Tibú/Norte de Santander & 2000 & 2011 \\
Mutatá & Tierra Alta/Córdoba & 2003 & 2016 \\
& & 1996 & 2009 \\
Chigorodó & Riosucio/Chocó & 2012 & 2012 \\
Dabeiba & & 2000 & 2011 \\
\hline
\end{tabular}

Fuente: $\quad$ SIRDEC/RND/INMLCF. Elaboración propia a partir de Cifuentes (2020).

Finalmente, las dos personas desaparecidas en el municipio de Puerto Berrio, correspondieron con dos hombres uno de 26 años, quien según relato del reportante, se encontraba desempleado y fue contratado para llevar un vehículo

10 En adelante, se tomará la sigla FARC-EP, para nombrar las Fuerzas Armadas Revolucionarias de Colombia-Ejército del Pueblo, de acuerdo a la denominación que, a partir de 1982, esta guerrilla adoptó y que se mantuvo hasta el año 2016, año en que se firman los acuerdos de paz con este grupo. Las menciones de este grupo en los años de contexto anteriores a 1982 en el presente documento, se tomará la sigla FARC. 
hasta Riohacha y no se supo más de su paradero, su cuerpo fue hallado siete años después (Tabla 4) en el municipio de Pelaya, César. El otro hombre, se trató de un joven de 20 años, quien fue llevado forzadamente junto con otros jóvenes a trabajar al departamento de Caquetá y once años después (Tabla 4) su cuerpo fue exhumado en una diligencia de exhumación en Belén de los Andaquíes de este departamento, la identificación de este joven fue mencionada en el libro Textos Corporales de la Crueldad (CNMH, 2014), donde describen algunas características halladas desde el contexto forense, sus restos mortales evidenciaron destrucción en cráneo, posiblemente por disparo, amputación del brazo derecho y disparo en abdomen.

\section{Flujos Intermunicipales}

Cerca del $13 \%$ de los casos presentaron movimientos espaciales entre municipios diferentes, dentro del mismo departamento de Antioquia. Específicamente 15 personas desparecidas en 12 municipios antioqueños, sus cuerpos fueron encontrados en diez municipios diferentes del mismo departamento. Así, una de las personas desaparecidas en el Carmen de Viboral y otra en el municipio de Argelia, sus cuerpos fueron hallados en el municipio de Sonsón. De igual manera, una de las personas desaparecidas en el municipio de Frontino y otra en el municipio San Pedro de Urabá, sus cuerpos se encontraron en el municipio de Turbo. Cuatro de los desaparecidos en el municipio de Granada, se hallaron muertos en el municipio de Cocorná; la única persona desaparecida caracterizada para el municipio de Campamento, su cuerpo fue hallado en el municipio de Briceño. Para el caso de los municipios de Dabeiba, Frontino, Mutatá y Nariño, una de las personas desaparecidas caracterizadas en cada uno de estos, sus cuerpos fueron hallados en los municipios de San Roque, Olaya, Nariño y Rionegro, respectivamente y finalmente, una de las personas desaparecidas en el municipio de Carmen de Viboral y otra en el municipio de Granada, sus cuerpos se encontraron en los municipios de La Unión y de San Carlos, respectivamente (Figura 13).

Las dos personas desaparecidas en el municipio del Carmen de Viboral, cuyos cuerpos fueron hallados en los municipios de Sonsón y la Unión, correspondieron a los de un hombre menor de edad y una mujer de 30 años, desaparecidos en 2002 y 2003, y hallados siete y nueve años después (Tabla 5), respectivamente. El menor de edad fue sacado de su casa por hombres armados y la mujer fue citada por el bloque Central Bolívar, se trataba de una mujer victimizada por diferentes violencias, fue desplazada cuando asesinaron a su esposo en el municipio de Granada, su familia fue amenazada y obligada a desplazarse. La persona desaparecida en el municipio de Argelia, se trató de una mujer mayor de edad, desaparecida en 1999, reclutada por las FARC-EP y hallada once años más tarde 
(Tabla 5), mediante exhumación de una fosa común en la vereda La Soledad, del municipio de Sonsón, entre personal de la Unidad de Justicia y Paz de Medellín y de la Fiscalía Seccional 178.

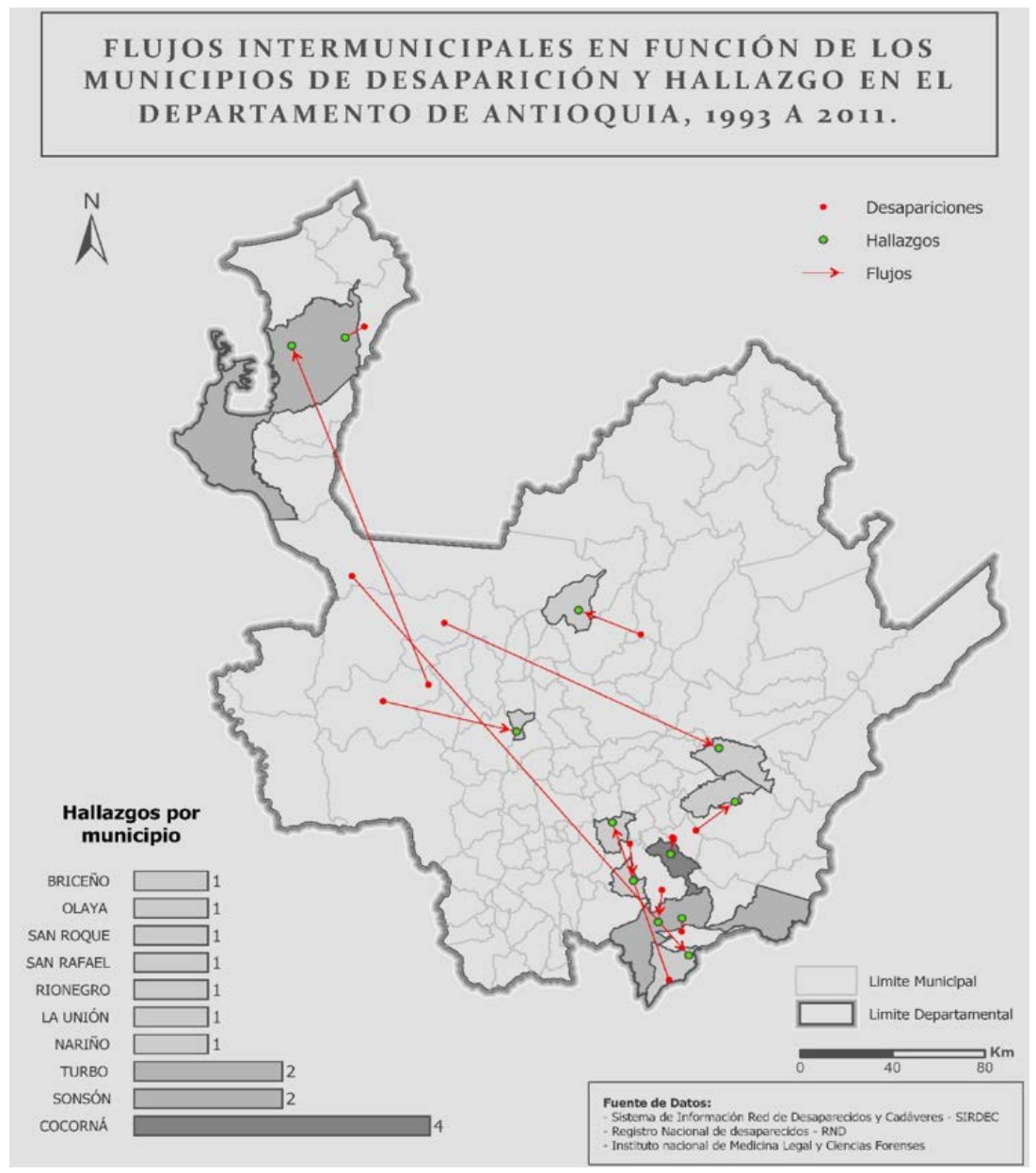

Figura 13. Flujos intermunicipales, trayectos desde el municipio de desaparición hasta el municipio de hallazgo, en el departamento de Antioquia entre 1993 y 2011. Elaboración propia a partir de Cifuentes (2020).

Dos personas desaparecidas en el municipio de Frontino, correspondieron a hombres mayores de edad. Uno de ellos fue desaparecido cuando se desplazaba hacia un lugar cercano del municipio Santafé de Antioquia, once años más tarde 
(Tabla 5) su cuerpo fue exhumado en el municipio de Olaya. El segundo hombre, se dirigía del corregimiento donde vivía, hacia una finca donde trabajaba, fue interceptado y desaparecido por paramilitares, once años después su cuerpo fue exhumado en el municipio de Turbo. En este municipio también fue hallada la persona desaparecida en el municipio de San Pedro de Urabá, después de 15 años (Tabla 5) de su desaparición, este hombre fue sacado de su casa por hombres armados. Su desaparición se debió, según versiones del postulado José Efraín Pérez Cardona alias "400", a que desobedeció una orden dada por alias "00" comandante de las AUC, que consistía en no poder desplazarse al sector Volcán Cacahual, siendo señalado como informante de la guerrilla y asesinado. Mediante diligencias de exhumación realizadas en el municipio de Briceño, por la Unidad de Justicia y Paz de la Fiscalía, en 2007, se halló el cuerpo de un hombre, correspondiente a la persona desparecida caracterizada para el municipio de Campamento, quien fuera interceptado por grupos paramilitares y bajado del vehículo en el que se transportaba.

Cinco de las personas desparecidas en el municipio de Granada, correspondieron con un hombre mayor de edad, sacado a la fuerza de su casa por hombres armados, cuyo cuerpo fue hallado cinco años después (Tabla 5) en el municipio de San Carlos por la Unidad de Justicia y Paz. Las otras cuatro personas desaparecidas, sus cuerpos fueron exhumados mediante diligencias de diferentes bóvedas del cementerio del municipio de Cocorná, entre cinco y seis años después (Tabla 5), las cuales correspondieron con una mujer de 15 años, cuya desaparición se atribuye al Ejército Nacional; tres hombres mayores de edad, dos de ellos hermanos que salieron a buscar agua y no regresaron y finalmente, un hombre mayor de edad, que fue sacado de la finca donde trabajaba por hombres de la guerrilla. Una de las dos personas desaparecidas caracterizadas en el municipio de Dabeiba, correspondió con un hombre mayor de edad, quien salió a caballo de su casa al mercado, una vecina encontró el caballo y lo llevó a sus familiares, quienes al buscarlo encontraron una prenda que llevaba con él, con orificios y huellas de sangre, nueve años después (Tabla 5) su cuerpo fue exhumado en el municipio de San Roque.

Una de las cuatro personas desaparecidas, caracterizadas en el municipio de Mutatá, correspondió con un menor de edad de doce años, quien después de irse de su casa a trabajar a un lugar cerca del corregimiento de Belén de Bajirá, su familia no tuvo más información de él, 20 años después (Tabla 5) su cuerpo fue exhumado en el municipio de Nariño. Finalmente, de los desaparecidos caracterizados en el municipio de Nariño, una persona correspondiente con un hombre de 33 años, su cuerpo fue hallado en el Municipio de Rionegro, cuatro años después (Tabla 5). Su desaparición se atribuye al frente 47 de las FARC-EP, reclutado cuando salió al pueblo, después de la toma guerrillera al municipio de Arboleda, Caldas. 
Tabla 5. Municipios de desaparición y hallazgo, a partir de los cuales se construyen los flujos intermunicipales y sus temporalidades

\begin{tabular}{lclc}
\hline $\begin{array}{l}\text { Municipio de } \\
\text { desaparición }\end{array}$ & $\begin{array}{c}\text { Año de } \\
\text { desaparición }\end{array}$ & $\begin{array}{c}\text { Municipio de } \\
\text { hallazgo }\end{array}$ & $\begin{array}{c}\text { Año de } \\
\text { hallazgo }\end{array}$ \\
\hline Mutatá & 1993 & Nariño & 2013 \\
Frontino & 1996 & Olaya & 2007 \\
San Pedro de & 1996 & Turbo & 2007 \\
Urabá & 1996 & Turbo & 2011 \\
Nariño & 1997 & Rionegro & 2001 \\
Argelia & 1999 & Sonsón & 2010 \\
Dabeiba & 2000 & San Roque & 2009 \\
El Carmen de & 2002 & Sonsón & 2009 \\
Viboral & 2003 & La Unión & 2012 \\
Campamento & 2003 & Briceño & 2007 \\
Granada & 2002 & San Carlos & 2007 \\
& 2004 & Cocorná & 2009 \\
& 2004 & Cocorná & 2010 \\
\hline
\end{tabular}

Fuente: $\quad$ SIRDEC/RND/INMLCF. Elaboración propia a partir de Cifuentes (2020).

\section{Singularidad espacial intramunicipal}

Del total de personas desaparecidas aparecidas muertas caracterizadas, el $80 \%$ de los casos (correspondiente a 90 casos concentrados en 16 municipios), presentó tanto la desaparición de la persona como el hallazgo del cuerpo, en el mismo municipio. Se observó que la totalidad de las personas desaparecidas caracterizadas en los municipios de Amalfi, Briceño, La Ceja, San Carlos, San Luis, Sonsón, Sopetrán, Turbo y Urrao, sus cuerpos fueron hallados en el mismo municipio de desaparición y correspondieron con 64 casos (Tabla 6). Los 26 casos (Tabla 7) restantes correspondieron con parte de los desaparecidos caracterizados en los municipios de Argelia, Chigorodó, Carmen de Viboral, Granada, Ituango, Nariño y San Pedro de Urabá. (Figura 14).

Las cuatro personas caracterizadas en el municipio de Amalfi, correspondieron a una mujer y tres hombres, desaparecidas entre 1999 y 2000 (Tabla 6). De acuerdo con los relatos de los hechos y a la información consignada en el seguimiento de los casos, estás personas fueron halladas alrededor de siete años más tarde (Tabla 6), mediante la misma labor de exhumación en una fosa común junto con otros cuerpos. Esta fosa fue localizada en la mina de Oro La Viborita a 20 minutos de Amalfi en la vía hacía Medellín (El Tiempo, 2007). Estas desapariciones consistieron en raptos forzados y según testimonio de uno de los 


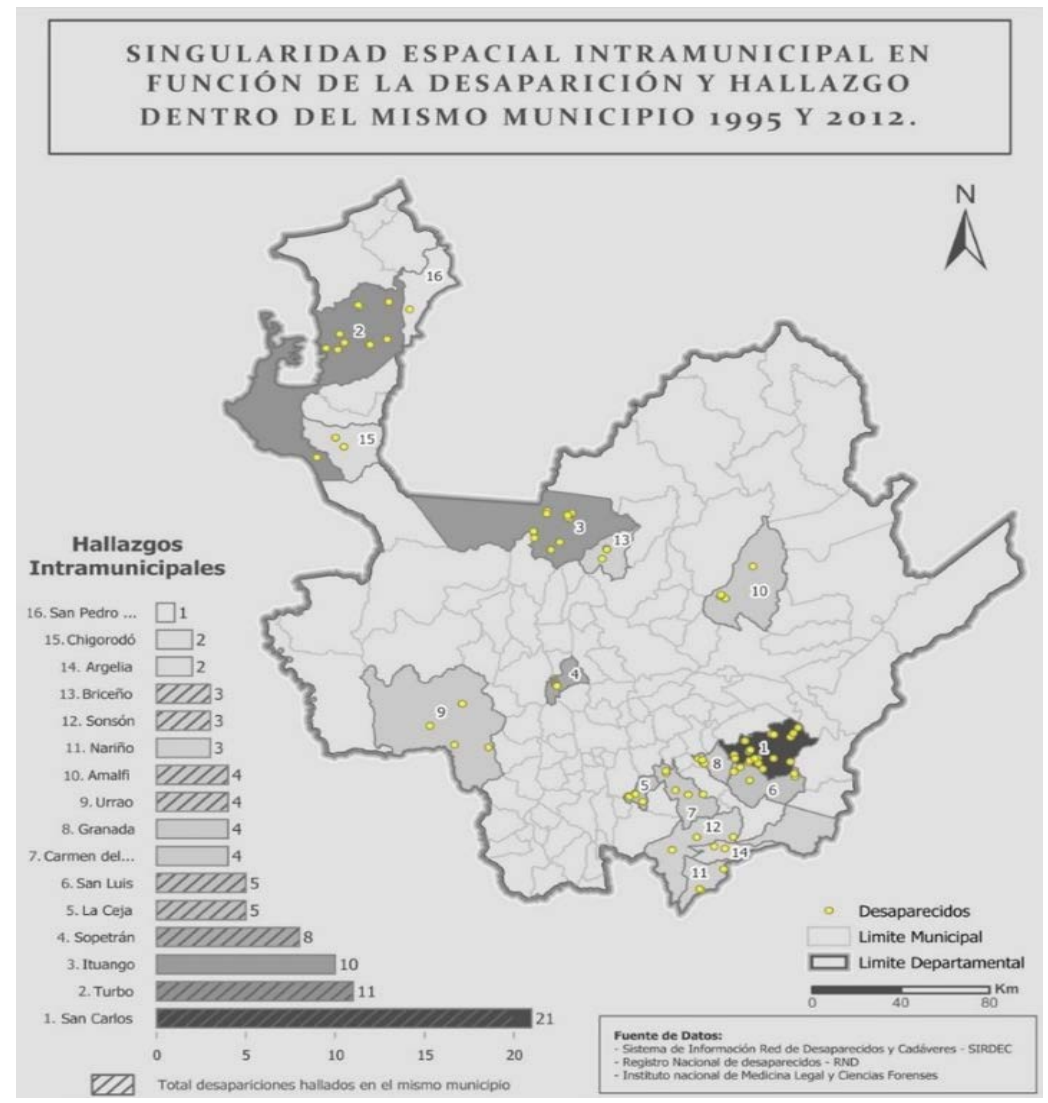

Figura 14. Singularidad espacial intramunicipal. Desapariciones y hallazgos en el mismo municipio del departamento de Antioquia, entre 1995 y 2012. Elaboración propia a partir de Cifuentes (2020).

fiscales relacionado en un reporte de prensa publicado pocos días posteriores a la diligencia de exhumación adelantada por la Unidad de Justicia y Paz, Fiscalía Medellín, mencionó que "[...] "La mayoría de los cuerpos estaban desmembrados y algunos tenían orificios por disparos [...]” (El Tiempo, 2007).

La materialidad de las desapariciones ocurridas en el municipio de Briceño, muestra a tres hombres mayores de edad, dos de ellos desaparecidos en circunstancias desconocidas y el tercero sacado de manera forzada por grupos paramilitares, entre 2000 y 2004; quienes fueron hallados mediante diligencias de exhumación (Tabla 6) realizadas en este municipio, por la Unidad de Justicia y Paz de la Fiscalía, en el año 2007. 
Las personas desaparecidas, caracterizadas para el municipio de la Ceja, correspondieron a cinco hombres cuyas edades al momento de la desaparición oscilaron entre los 18 y los 48 años. De estos, dos eran hermanos quienes fueron desaparecidos en circunstancias desconocidas pero atribuidas a grupos paramilitares en 2000, sus cuerpos esqueletizados fueron exhumados siete años después, por la Unidad de Justicia y Paz de la Fiscalía. Un tercer hombre fue sacado de su casa por paramilitares, en la vereda Romeral en 2003, su cuerpo fue hallado mediante exhumación en la vereda La Miel en 2011. Por información suministrada por un desmovilizado, los otros dos hombres fueron sacados del casco urbano en 2005 y posteriormente exhumados en la vereda La Playa en 2009 (Tabla 6).

San Carlos fue el municipio con mayor número personas desaparecidas aparecidas muertas, en total se caracterizaron 21 personas, 18 hombres y tres mujeres, entre estos, dos menores de edad, pero en su mayoría adultos entre los 30 y 77 años. De acuerdo con los relatos proporcionados por los reportantes, estas desapariciones se dieron entre los años 2000 a 2005, bajo modalidades de interceptación cuando las personas se desplazaban de un lugar a otro, o posterior a citaciones por jefes de grupos armados o por raptos en sus casas o en sus lugares de trabajo, por grupos armados tanto paramilitares, como guerrilla. Los cuerpos de estas 21 personas fueron hallados en un periodo entre 2007 a 2011 (Tabla 6), mediante exhumaciones realizadas por la Unidad de Justicia y Paz de la Fiscalía.

En el municipio de San Luis se caracterizaron cinco hombres mayores de edad desaparecidos aparecidos muertos, cuyas desapariciones ocurrieron entre los años 2001 a 2004, enmarcadas en las modalidades similares a las descritas para el municipio de San Carlos, sus cuerpos fueron hallados mediante diligencias de exhumación entre 2009 y 2014 (Tabla 6). Para el municipio de Sonsón, se caracterizaron tres hombres mayores de edad desaparecidos en 1997, 2003 y 2005. Estas desapariciones fueron atribuidas a grupos armados, entre ellos guerrillas. Sus cuerpos fueron exhumados en 2009 y 2010 (Tabla 6).

Los casos de personas desaparecidas aparecidas muertas caracterizadas en el municipio de Sopetrán muestran una tendencia diferencial, correspondiente con una desaparición múltiple, en un solo evento, en el cual, siete hombres y una mujer entre los 19 y 42 años fueron sacados de una finca en la vereda El Rodeo por hombres armados en 2011. Un mes después sus cuerpos son exhumados de tres fosas en la vereda El Pomar. Estos hechos fueron atribuidos a dinámicas criminales y a modos de acción en el "ajuste de cuentas" entre bandas criminales características del conflicto urbano expresado en el área metropolitana. Estas ocho desapariciones se pueden leer por fuera de la tendencia temporal que expresan las desapariciones forzadas en el escenario de conflicto armado rural, pues se da posterior al descenso que esta violencia presentó hacia 2009 (Figura 8). 
Tabla 6. Municipios cuya totalidad de desaparecidos caracterizados fueron hallados en el mismo municipio. Espacialidad itramunicipal

\begin{tabular}{|c|c|c|c|c|c|c|c|c|c|}
\hline \multirow{2}{*}{$\begin{array}{c}\text { Municipio desaparición y } \\
\text { hallazgo/ } \\
\text { Año de desaparición }\end{array}$} & \multicolumn{9}{|c|}{ Año de hallazgo } \\
\hline & $\underset{8}{\tilde{8}}$ & $\underset{\infty}{\infty}$ & $\widetilde{8}$ & 苂 & 尽 & $\stackrel{\widetilde{D}}{\sim}$ & $\underset{\omega}{\stackrel{\sim}{\omega}}$ & $\underset{\triangleright}{\stackrel{D}{\triangle}}$ & $\begin{array}{c}\text { Total de } \\
\text { casos }\end{array}$ \\
\hline Amalfi & 4 & - & - & - & - & - & - & - & 4 \\
\hline 1999 & 2 & - & - & - & - & - & - & - & 2 \\
\hline 2000 & 2 & - & - & - & - & - & - & - & 2 \\
\hline Briceño & 3 & - & - & - & - & - & - & - & 3 \\
\hline 2000 & 1 & - & - & - & - & - & - & - & 1 \\
\hline 2002 & 1 & - & - & - & - & - & - & - & 1 \\
\hline 2004 & 1 & - & - & - & - & - & - & - & 1 \\
\hline LaCeja & 2 & - & 2 & - & 1 & - & - & - & 5 \\
\hline 2000 & 2 & - & - & - & - & - & - & - & 2 \\
\hline 2003 & - & - & - & - & 1 & - & - & - & 1 \\
\hline 2005 & - & - & 2 & - & - & - & - & - & 2 \\
\hline San Carlos & 4 & 2 & 5 & 2 & 7 & 1 & - & - & 21 \\
\hline 2000 & - & - & 1 & - & 3 & - & - & - & 4 \\
\hline 2001 & 2 & 1 & - & 1 & - & - & - & - & 4 \\
\hline 2002 & - & 1 & 1 & 1 & 1 & 1 & - & - & 5 \\
\hline 2003 & 1 & - & 1 & - & - & - & - & - & 2 \\
\hline 2004 & 1 & - & 1 & - & - & - & - & - & 2 \\
\hline 2005 & - & - & 1 & - & 3 & - & - & - & 4 \\
\hline San Luis & - & - & 1 & 2 & - & - & - & 2 & 5 \\
\hline 2001 & - & - & 1 & - & - & - & - & - & 1 \\
\hline 2002 & - & - & - & 1 & - & - & - & - & 1 \\
\hline 2003 & - & - & - & 1 & - & - & - & 1 & 2 \\
\hline 2004 & - & - & - & - & - & - & - & 1 & 1 \\
\hline Sonsón & - & - & 2 & 1 & - & - & - & - & 3 \\
\hline 1997 & - & - & - & 1 & - & - & - & - & 1 \\
\hline 2003 & - & - & 1 & - & - & - & - & - & 1 \\
\hline 2005 & - & - & 1 & - & - & - & - & - & 1 \\
\hline Sopetrán & - & - & - & - & 8 & - & - & - & 8 \\
\hline 2011 & - & - & - & - & 8 & - & - & - & 8 \\
\hline Turbo & 4 & 3 & - & 2 & - & - & 1 & 1 & 11 \\
\hline 1995 & 2 & - & - & - & - & - & - & - & 2 \\
\hline 1996 & 1 & - & - & - & - & - & - & - & 1 \\
\hline 1997 & - & 2 & - & 1 & - & - & 1 & - & 4 \\
\hline 1998 & - & - & - & 1 & - & - & - & 1 & 2 \\
\hline 2001 & 1 & - & - & - & - & - & - & - & 1 \\
\hline 2003 & - & 1 & - & - & - & - & - & - & 1 \\
\hline Urrao & 3 & - & 1 & - & - & - & - & - & 4 \\
\hline 1994 & 1 & - & - & - & - & - & - & - & 1 \\
\hline 1995 & 1 & - & - & - & - & - & - & - & 1 \\
\hline 1998 & - & - & 1 & - & - & - & - & - & 1 \\
\hline 2004 & 1 & - & - & - & - & - & - & - & 1 \\
\hline Total de casos & 20 & 5 & 11 & 7 & 16 & 1 & 1 & 3 & 64 \\
\hline
\end{tabular}

Fuente: SIRDEC/RND/INMLCF. Elaboración propia a partir de Cifuentes (2020). 
La materialidad de la desaparición forzada en el municipio de Turbo, se caracterizó en once víctimas, diez hombres y una mujer mayores de edad, desaparecidas entre 1995 y 2003, cuyos cuerpos fueron exhumados entre 2007 y 2014 (Tabla 6), mediante diligencias de exhumación, algunas de ellas adelantadas por la Unidad de Justicia y Paz. Cinco de las víctimas fueron sacadas de sus casas por paramilitares, otra víctima fue interceptada y raptada por paramilitares cuando se desplazaba a caballo hacia una vereda, quienes llevaban amarrada a una de las víctimas que habían sacado de su casa; otra fue citada por un integrante del bloque Bananeros que operaba en la zona. No hay claridad frente a las circunstancias de desaparición de las otras cuatro personas, pero en dos de los casos, los hechos fueron atribuidos al bloque Bananeros.

Las personas desaparecidas en el municipio de Urrao, correspondieron con cuatro hombres mayores de edad, quienes desaparecieron entre 1994 y 2004 y posteriormente sus cuerpos fueron hallados mediante diligencias de exhumación realizadas en 2007 y 2009 (Tabla 6). En dos de los casos se desconocen las circunstancias de desaparición; sin embargo, los hechos se atribuyen a paramilitares y en uno de ellos, al bloque Cacique Nutibara vinculado a las Autodefensas Campesinas de Córdoba y Urabá (AUUC). ${ }^{11}$ Los hechos de los otros dos casos fueron atribuidos a grupos armados.

Las dos personas desaparecidas en el municipio del Carmen de Viboral, cuyos cuerpos fueron hallados en los municipios de Sonsón y la Unión, correspondieron a los de un hombre menor de edad y una mujer de 30 años, desaparecidos en 2002 y 2003, y hallados siete y nueve años después (Tabla 5), respectivamente. El menor de edad fue sacado de su casa por hombres armados y la mujer fue citada por el bloque Central Bolívar, se trataba de una mujer victimizada por diferentes violencias, fue desplazada cuando asesinaron a su esposo en el municipio de Granada, su familia fue amenazada y obligada a desplazarse. La persona desaparecida en el municipio de Argelia, se trató de una mujer mayor de edad, desaparecida en 1999, reclutada por las FARC-EP y hallada once años más tarde (Tabla 5), mediante exhumación de una fosa común en la vereda La Soledad, del municipio de Sonsón, entre personal de la Unidad de Justicia y Paz de Medellín y de la Fiscalía Seccional 178.

Las dos personas desaparecidas en el municipio de Argelia con espacialidad intramunicipal, correspondieron con dos hombres mayores de edad, desaparecidos en 1995 y 2004, uno en circunstancias desconocidas atribuidas a paramilitares, hallado en exhumación realizada en la vereda El Tesoro, del municipio de Argelia a orillas de una quebrada en 2008 y el segundo hombre, raptado por el frente 47 de las FARC-EP, por órdenes de alias Karina, quien fue

11 Estos dos grupos (Bloque Cacique Nutibara y Autodefensas Campesinas de Córdoba y Urabá), corresponden con estructuras paramilitares que operaban en la zona. 
hallado en una fosa común exhumada en la vereda Guayaquil del municipio de Argelia, también en 2008 (Tabla 7) por la Unidad de Justicia y Paz.

Para el municipio de Chigorodó, se caracterizaron dos hombres mayores de edad desaparecidos en circunstancias desconocidas en 1996 y 2002, en el último de ellos, los hechos se atribuyen a paramilitares. Sus cuerpos fueron hallados en 2007 (Tabla 7) mediante diligencias de exhumación.

Del municipio de Carmen de Viboral, se caracterizaron cuatro hombres mayores de edad, desaparecidos entre 2001 y 2003 (Tabla 7), dos de ellos fueron interceptados cuando uno se dirigía a realizar un trabajo y el otro, camino del trabajo a su casa. Los otros dos hombres fueron citados. Los hechos en tres de las cuatro desapariciones, fueron atribuidas al frente 47 de las FARC-EP, cuyos cuerpos fueron hallados en fosas comunes en la vereda Brazil en 2009. El cuerpo del cuarto hombre fue exhumado en 2012 en la vereda Villajuelitos.

Las cuatro personas desaparecidas caracterizadas en el municipio de Granada, correspondieron a dos mujeres y a dos hombres mayores de edad, una de ellas fue bajada por paramilitares junto con su esposo del carro en el que se transportaban, la otra mujer fue raptada por el frente noveno de las FARC-EP, señalada de ser paramilitar. Uno de los hombres, fue bajado junto con otras personas del transporte en el que se desplazaba. El otro hombre fue raptado por paramilitares cuando salió de su casa a trabajar. Estas cuatro personas fueron desaparecidas en la misma fecha del año 2003 y sus cuerpos fueron hallados en diligencias de exhumación realizadas en diferentes fosas en 2007 (Tabla 7).

Las diez personas desaparecidas aparecidas muertas del municipio de Ituango entre 2000 y 2010, sus cuerpos se hallaron mediante diferentes diligencias de exhumación, entre 2007 y 2011 (Tabla 7). De los diez cuerpos encontrados, siete pertenecían a cinco hombres y una mujer, quienes fueron exhumados en el corregimiento de La Granja del municipio de Ituango, durante la misma diligencia, realizada por la Unidad Nacional de Justicia y Paz en 2010, exceptuando el cuerpo de la mujer, quien fue hallada en 2005 en una diligencia informada por la Unidad Básica de Investigación Criminal del mismo municipio, quien según el relato de los hechos fue reclutada por las FARC-EP en el corregimiento de Santa Rita.

Según nota periodística (El Colombiano, 2010), uno de los cinco hombres exhumados, se trataba de un educador de 46 años, quien fue secuestrado por integrantes del frente 18 de las FARC-EP, asesinado e inhumado por los guerrilleros en la vereda Santa Lucía, alrededor de la fosa fueron sembradas minas antipersonas para dificultar las labores de hallazgo. De igual manera, los tres cuerpos restantes, pertenecían a una mujer y dos hombres; dos de ellos, una mujer y un hombre desaparecidos en 2002 y 2005 respectivamente, fueron exhumados también por la Unidad Nacional de Justicia y Paz en 2008 en el corregimiento de Santa Rita. De acuerdo con el relato de los hechos, la mujer fue 
raptada de su casa y el hombre interceptado cuando se desplazaba en una motocicleta, ambos hechos atribuidos al frente 18 de las FARC-EP. Así mismo, el segundo hombre correspondía a una persona desplazada del corregimiento de Santa Rita y al regresar después de varios años, fue desparecido, hecho atribuido

Tabla 7. Municipios con parte de desaparecidos caracterizados hallados en el mismo municipio. Espacialidad Intramunicipal

\begin{tabular}{|c|c|c|c|c|c|c|c|c|}
\hline \multirow{2}{*}{$\begin{array}{c}\text { Municipio de desaparición y } \\
\text { de hallazgo/Año de } \\
\text { desaparición }\end{array}$} & \multicolumn{8}{|c|}{ Año de hallazgo } \\
\hline & $\begin{array}{l}\text { 오 } \\
\text { ज }\end{array}$ & $\underset{\mathrm{D}}{\stackrel{\mathrm{D}}{ }}$ & స్ & $\widetilde{8}$ & $\underset{\sigma}{\stackrel{\sim}{\circ}}$ & $\underset{\sim}{\stackrel{2}{\circ}}$ & $\underset{\sim}{\sim}$ & $\begin{array}{c}\text { Total de } \\
\text { casos }\end{array}$ \\
\hline Argelia & - & - & 2 & - & - & - & - & 2 \\
\hline 1995 & - & - & 1 & - & - & - & - & 1 \\
\hline 2004 & - & - & 1 & - & - & - & - & 1 \\
\hline Chigorodó & - & 2 & - & - & - & - & - & 2 \\
\hline 1996 & - & 1 & - & - & - & - & - & 1 \\
\hline 2002 & - & 1 & - & - & - & - & - & 1 \\
\hline El Carmen de Viboral & - & - & - & 3 & - & - & 1 & 4 \\
\hline 2001 & - & - & - & 1 & - & - & - & 1 \\
\hline 2002 & - & - & - & 1 & - & - & - & 1 \\
\hline 2003 & - & - & - & 1 & - & - & 1 & 2 \\
\hline Granada & - & 4 & - & - & - & - & - & 4 \\
\hline 2003 & - & 4 & - & - & - & - & - & 4 \\
\hline Ituango & 1 & - & 2 & - & 6 & 1 & - & 10 \\
\hline 2000 & - & - & - & - & 2 & - & - & 2 \\
\hline 2002 & - & - & 1 & - & 1 & - & - & 2 \\
\hline 2003 & - & - & - & - & 1 & - & - & 1 \\
\hline 2004 & - & - & - & - & 1 & - & - & 1 \\
\hline 2005 & 1 & - & 1 & - & - & - & - & 2 \\
\hline 2009 & - & - & - & - & 1 & - & - & 1 \\
\hline 2010 & - & - & - & - & - & 1 & - & 1 \\
\hline Nariño & - & - & 3 & - & - & - & - & 3 \\
\hline 2000 & - & - & 1 & - & - & - & - & 1 \\
\hline 2002 & - & - & 1 & - & - & - & - & 1 \\
\hline 2003 & - & - & 1 & - & - & - & - & 1 \\
\hline San Pedro De Urabá & - & - & - & - & 1 & - & - & 1 \\
\hline 1997 & - & - & - & - & 1 & - & - & 1 \\
\hline Total de casos & 1 & 6 & 7 & 3 & 7 & 1 & 1 & 26 \\
\hline
\end{tabular}

Fuente: SIRDEC/RND/INMLCF. Elaboración propia a partir de Cifuentes (2020). 
a la guerrilla. Su cuerpo fue exhumado en 2011 en la vereda El Tinto del corregimiento del Aro, por miembros de la Brigada Móvil 25 de la Fuerza Aérea colombiana y por técnicos en criminalística del CTI de Medellín.

Se caracterizaron tres personas desaparecidas aparecidas muertas del municipio de Nariño correspondientes a tres hombres mayores de edad, desaparecidos en 2000, 2002 y 2003, cuyos cuerpos se hallaron en 2008 (Tabla 7) mediante diligencias de exhumación realizadas por la Unidad de Justicia y Paz. Los tres hechos de desaparición se atribuyeron al frente 47 de las FARC-EP, al mando de Nelly Ávila Moreno alias "Karina".

Finalmente, para el municipio de San Pedro de Urabá, se caracterizó un caso con este tipo de espacialidad intramunicipal. Se trató de un hombre mayor de edad, desaparecido en 1997 por hombres pertenecientes a las autodefensas y su cuerpo hallado mediante diligencia de exhumación realizada por la Unidad de Justicia y Paz en 2010 (Tabla 7).

Los vacíos de información hacen que indagar la espacialidad de la materialidad de la desaparición forzada a escalas con mayor especificidad tenga dificultades (Cifuentes, 2020). No obstante, a través de la información disponible, dentro de la singularidad espacial intramunicipal caracterizada, se pudieron establecer movimientos espaciales en flujo interveredales y espacialidades puntuales intraveredales de la siguiente manera:

- Flujos Interveredales. Quince de los casos mencionados presentaron movimientos espaciales de flujo interveredal (Figura 15); es decir, quince personas fueron desaparecidas en veredas diferentes a las veredas en las que fueron encontrados sus cuerpos.

- Espacialidad Puntual Veredal. En 21 casos, se puedo establecer que la desaparición de las personas y el posterior hallazgo de los cuerpos, se dio en la misma vereda, mostrando una espacialidad puntual (Figura 16) para esa escala específica.

La singularidad espacial intramunicipal, en la que se evidenciaron movimientos interveredales y puntualidades intraveredales, expresada por la mayoría de los casos analizados; puede sugerir dos características, una primera que se va a relacionar de alguna manera, con la eficiencia en la desaparición y ocultamiento de los cuerpos por parte de los perpetradores, en tanto es más eficiente para la dinámica del conflicto que la desaparición de la persona no implique largos desplazamientos espaciales o temporales, favoreciendo la impunidad perseguida (Cifuentes, 2020). De acuerdo con esto y como segunda característica, podría pensarse entonces que el hallazgo de los cuerpos de las personas desaparecidas en el contexto del conflicto armado rural, pueda orientarse hacia lugares cercanos al de la desaparición. 


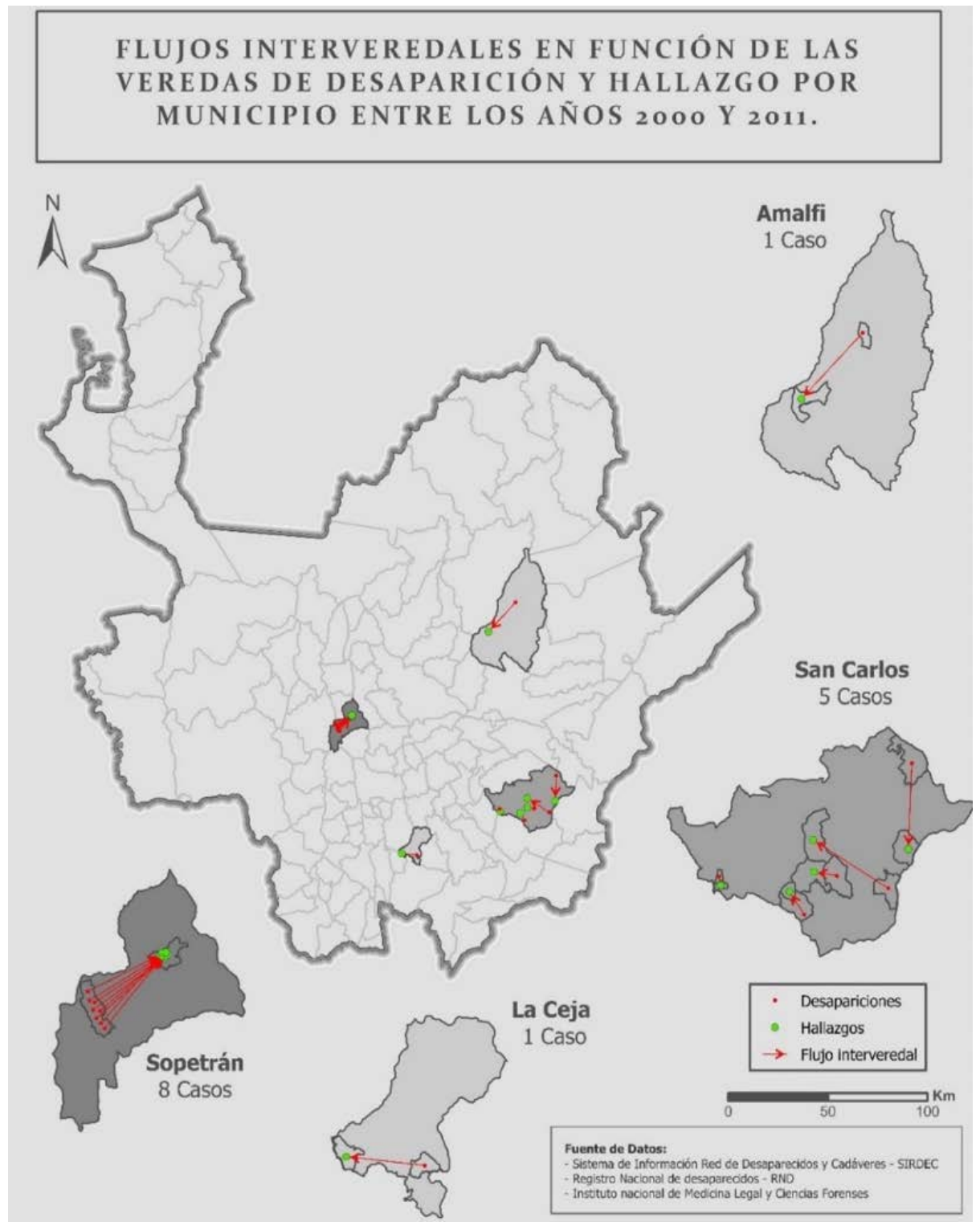

Figura 15. Flujos Interveredales. Desapariciones y hallazgos en veredas diferentes, dentro de la singularidad espacial intermunicipal, entre los años 2000 y 2011. Elaboración propia a partir de Cifuentes (2020). 


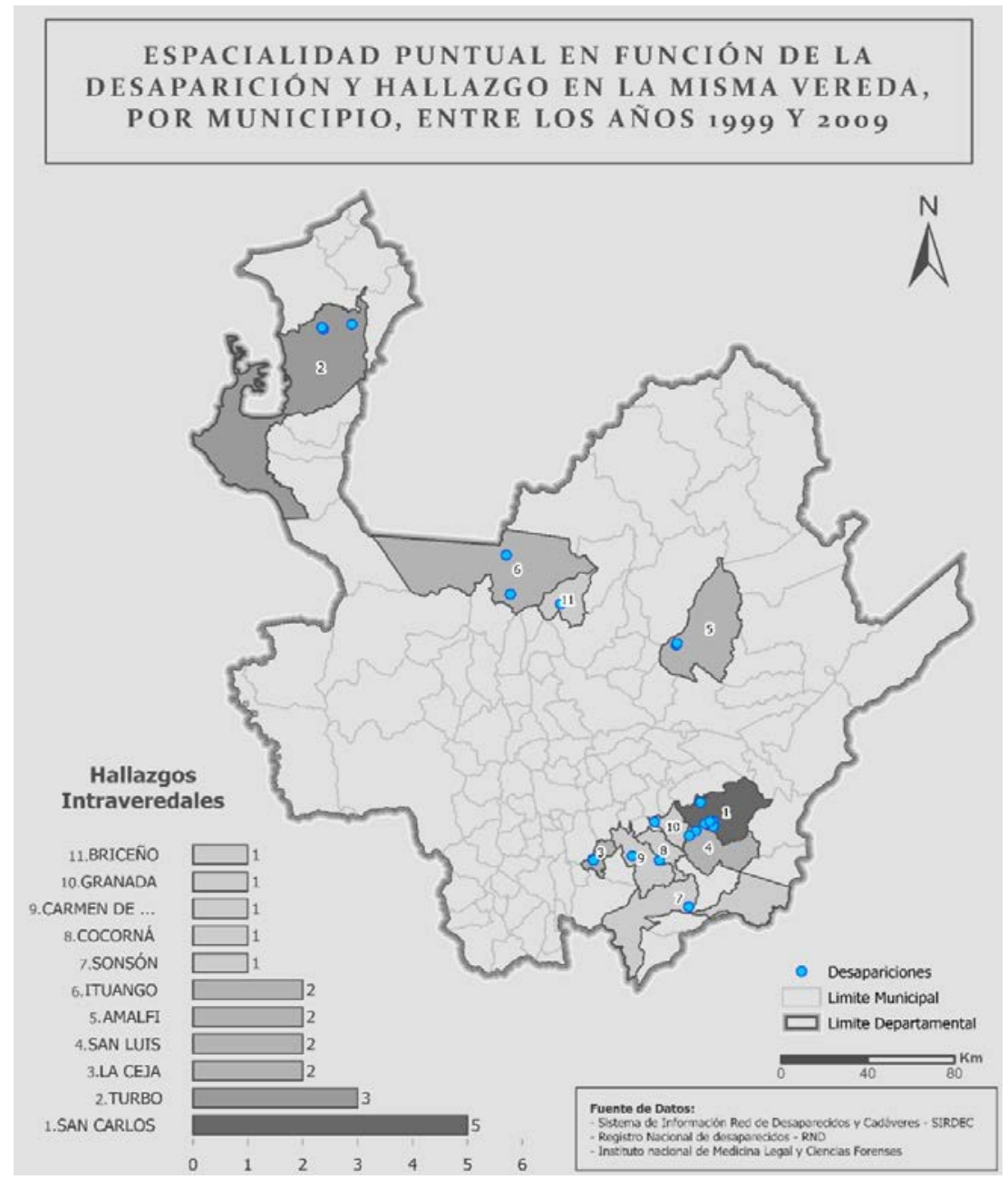

Figura 16. Espacialidad puntual veredal. Desapariciones y hallazgos en la misma vereda, dentro de la singularidad espacial intramunicipal, entre 1999 y 2009. Elaboración propia a partir de Cifuentes (2020).

\section{La materialidad de la desaparición forzada desde el espacio no absoluto y relativo a la espacialidad vivida y complejidad relacional del espacio}

El concepto de espacio y tiempo como no absolutos, se propone desde su evolución tipológica, partiendo desde la conceptualización misma de espacio absoluto concomitante a un tiempo absoluto, de raíz newtoniana, vistos desde una perspectiva matematizada del tiempo y una visión geométrica del espacio 
(Silveira, 2013). Allí, los objetos tienen localizaciones exactas referidas a las tres coordenadas que lo componen, cuyas distancias serán fijas y permanentes, al mejor estilo de un espacio meramente contenedor. El cambio epistemológico en estos conceptos lo plantearía la teoría de la relatividad desarrollada y propuesta por Einstein, al plantear que no es posible disociar las coordenadas de un cuerpo en el espacio de las coordenadas del mismo cuerpo en el tiempo; para esta teoría, tampoco será posible ver el mundo como una multiplicidad de partículas en movimiento, sino como una multiplicidad de acontecimientos sucedidos en $n$ dimensiones. No existen entonces localizaciones absolutas o estáticas, pues están en continuo movimiento, en función de las características del objeto; así el espacio relativo no será independiente de los objetos, este se definirá permanentemente en función de los objetos que lo conforman; es decir, los cambios dados en el objeto serán así en el espacio, con un carácter abstracto por encima del absoluto (Luna, 2010).

Al asumir esta tipología de espacio relativo, por lo tanto, abstracto, su estudio y entendimiento cambia, incluyendo las relaciones entre los objetos, por ejemplo, relaciones en flujos y distribuciones (Avendaño, 2013, 2018). Se reconoce entonces que, al tener $n$ coordenadas asociadas a un objeto, se comprende de igual manera, que este se compone por $n$ variables, corriendo el riesgo que en este espacio existan variables ocultas que quizá no formen parte de esos objetos, pero sí del comportamiento de los mismos (Luna, 2010). Ello está en la línea de lo que Avendaño (2018) ha tipificado como toporepresentaciones, o todo ese conjunto y sistema de significados e imaginarios creados sobre y del espacio.

Para Santos (1986), entender el espacio y el tiempo como relativos, permite ver entonces al espacio como un sistema de relaciones, donde el tiempo se impone como una dimensión esencial. Bagú (1986), plantea el espacio como un fragmento de la realidad social hecho de la misma materia que el tiempo. Lo dicho por Santos sobre el sistema de relaciones y lo expresado por Bagú, sobre la realidad social, implica incluir la experiencia humana en el carácter social de las relaciones. Por su parte, para la fenomenología no es posible llegar a un entendimiento de espacio y el tiempo, meramente desde la experiencia técnica y racional, sin considerar la experiencia humana en la totalidad. Es así como el espacio y el tiempo vividos, hayan sido para su momento, poco integradas en las reflexiones fenomenológicas (Buttimer, 1979). Actualmente y para la ciencia geográfica, estos elementos son esenciales, pues tanto la relatividad del espaciotiempo inmersos en una racionalidad histórica, van a estar dinamizados por una acción humana y social vivida, dentro de un espacio geográfico multiescalar, en una complejidad de redes, de acontecimientos y relacionamientos.

A partir de los planteamientos anteriores, es posible ver, no solo en la caracterización descrita -soportada en parte, por los relatos de los reportantes familiares de las víctimas y desde algunas de las versiones de responsabilidad por 
parte de los postulados en los escenarios de verdad que se alcanzan en una justicia transicional-, también en lo que muestra de alguna manera la acción estatal -desde la operatividad en la normatividad y política pública diseñada-, que la desaparición forzada -suscrita en este caso, en un escenario de conflicto armado y en una espacialidad rural-, se materializa en un entramado relacional y multiescalar complejo (Figura 17), marcado por circunstancias que explícitas o no, dinamizan, configuran y construyen el espacio en diferentes territorialidades y es precisamente esta complejidad la que establece que el espacio de la desaparición forzada, no es absoluto sino relativo (Cifuentes, 2020). Así, estos lugares y tiempos de desaparición y hallazgo, dibujan en el espacio flujos multiescalares: interdepartamentales, intermunicipales, interveredales; al igual que, puntualidades espaciales intramunicipales e intraveredales en temporalidades heterogéneas, mostrando una relatividad espacio-temporal dentro de un espacio relacional; pues estos flujos o trayectorias, no solo se descifran en la plasticidad espacial y temporal, también lo hacen, desde las singularidades entretejidas en las espacialidades vividas (Cifuentes, 2020).

Sobre esto último, es importante decir que el potencial violento de la desaparición forzada expone un tránsito no homogéneo, desde un espacio relativizado por las vivencias experimentadas. Inicialmente se podrá pensar en una espacialidad indicada por las coordenadas físicas que marcan los lugares de los acontecimientos de desaparición y por las coordenadas físicas de los lugares donde posteriormente se hallaron los restos mortales de estas personas desaparecidas, en un tiempo no absoluto definido por dos momentos, la temporalidad inicial de la desaparición y la temporalidad posterior del hallazgo; cuya dimensión espacial, se nutre y aumenta por las circunstancias que circundan estos sucesos. Por ejemplo, como ocurre al evidenciar las vivencias entre unos sujetos de acción y poder que deciden por qué y a quiénes desaparecer en el espacio-tiempo -los cuales irrumpen, amenazan, atemorizan, raptan, desaparecen y asesinan usando perversas modalidades de muerte-, infringidas a otros sujetos sometidos y objetivados, quienes en su tránsito de la vida a la muerte recrean otra multiplicidad de relaciones como las reacciones posibles de resistencia, rechazo e intentos de defensa hacia el agresor, o reacciones de súplica, sufrimiento, llanto, miedo, dolor, de angustia ante la posibilidad de no volver a ver a sus familiares, y porque no, reacciones espirituales, oraciones y encomendaciones desde sus creencias culturales o religiosas. Sujetos que, a su vez, se configuran en la memoria histórica como desaparecidos de un plano espacial y temporal, quienes al mismo tiempo permanecen en su forma no vital en el espacio y en el tiempo y que al ser hallados posteriormente muertos, plantearán nuevas relaciones a esa dimensionalidad espacial.

De igual manera, las espacialidades vividas se dinamizarán por las relaciones derivadas de las acciones de quienes sobreviven, padecen y caminan la 
incertidumbre del acontecimiento, en las vivencias de dolor, denuncia, búsqueda y exigencia de verdad y justicia para su ser querido desaparecido. Estas vivencias espaciales, igualmente un tipo de toporepresentaciones (Avendaño, 2018), también estarán dadas por quienes intervienen en la labor de ubicación de lugares de exhumación (declaraciones de verdad de los perpetradores-postulados y verdad desde los familiares); así como, por parte de quienes llevan a cabo la recuperación de los restos mortales (personal técnico-institucional y/o ONG's en el marco de un contexto humanitario); las cuales se yuxtaponen estableciendo una complejidad relacional de poder de unos sobre otros en el espacio, es decir, dicha materialidad se amplifica en una producción inagotada del espacio por acciones de poder, las que se traducirán en territorialidades.

\section{Conclusiones}

El texto elaborado, en torno a la desaparición forzada en el departamento de Antioquia para el período 1993-2016, muestra la construcción de territorialidades, a partir de las relaciones dadas en el curso de su materialidad, temporalidad y los significados dados al fenómeno. De esta manera, se concluye que:

- La materialidad de la desaparición forzada sucedida en el departamento de Antioquia se suscribió predominantemente en un contexto territorial-rural, dentro de escenarios espaciales y temporales de la dinámica del conflicto armado colombiano.

- La población caracterizada, se enmarcó en patrones generales descritos en los diferentes análisis hechos sobre este conflicto; siendo principalmente los hombres campesinos las víctimas mortales y las mujeres, las víctimas sobrevivientes de esta violencia.

- La singularidad espacial intramunicipal, desde los movimientos interveredales y las espacialidades puntuales intraveredales, expresada en la mayoría de los casos caracterizados, presenta dos elementos en la lógica del conflicto armado rural, el primero de ellos se relaciona con lo que podría denominarse, eficiencia en la desaparición y ocultamiento de los cuerpos por parte de los perpetradores, pues para la dinámica del conflicto, será mucho más eficiente que la desaparición de la persona no implique largos desplazamientos espaciales o temporales, garantizando la impunidad perseguida. En este sentido y como segundo elemento, podría pensarse entonces que el hallazgo de los cuerpos de las personas desaparecidas en dicho contexto, pueda orientarse hacia lugares cercanos al de la desaparición.

- Tanto los flujos como las puntualidades espaciales que mostró la materialidad de la desaparición forzada en el espacio geográfico antioqueño, evidencian una complejidad relacional que amplifica la dimensión espacial en las 
relaciones vivenciales experimentadas. Permitiendo ver que las territorialidades derivadas sucederán en un espacio-tiempo no absoluto, pues este será relativo en función de la multiplicidad de relaciones dadas, ocultas y por darse en los territorios, como se sintetiza en el siguiente esquema (Figura 17).

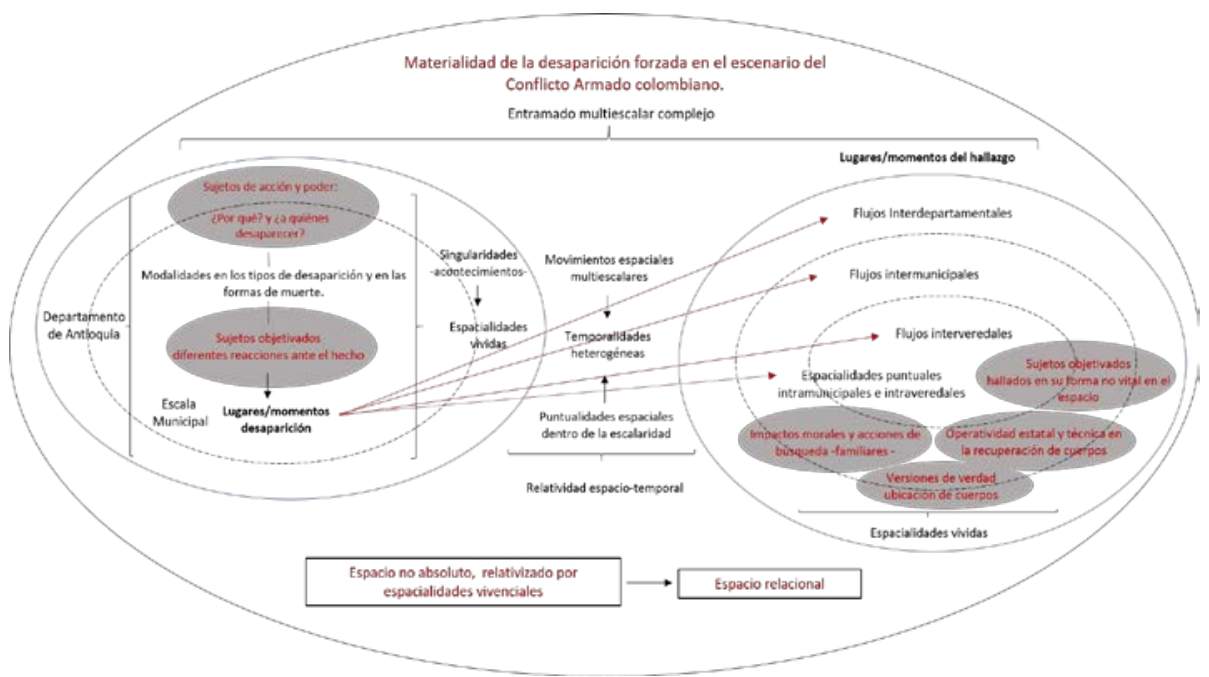

Figura 17. Espacio relativo en la complejidad relacional de las vivencias espaciales, expresado en territorialidades.

\section{Referencias}

Avendaño, J. (2011). Representaciones y expresiones territoriales de la pobreza urbana en el sur de Bogotá D.C. (Localidades de Ciudad Bolívar, San Cristóbal y Usme). Tesis de maestría en Desarrollo, territorio y sociedad, Escuela de Altos Estudios en Ciencias Sociales (EHESS), París.

(2013). Sobre las representaciones, los imaginarios y las identidades territoriales de los jóvenes respecto a la pobreza en Bogotá. Revista Rostros \& Rastros, 5(9), 49-57. Bogotá: Instituto de Estudios del Ministerio Público, Procuraduría General de la Nación.

(2018). Toporrepresentaciones: imaginarios, significados y representaciones socioespaciales. Temas y problemas de geografía humana: una perspectiva contemporánea. Colombia: Empresa Editorial Universidad Nacional de Colombia, 321-357.

Bagu, S. (1986). Tiempo, realidad social y conocimiento. México: Siglo XXI. En Silveira, M. (2013), Tiempo espacio en geografía: dilemas y reflexiones. Geografía Norte Grande, 9-29. 
Buttimer, A. (1979). Le temps, l'espace et le monde vécu. L'Espace Géographique, (4), 243254. En Silveira, M. (2013). Tiempo espacio en geografía: dilemas y reflexiones. Geografía Norte Grande, 9-29.

Centro Nacional de Memoria Histórica (CNMH)(2014). Textos corporales de la crueldad. Memoria histórica y antropología forense. Bogotá, Colombia, 256.

(2016). Hasta encontrarlos, El drama de la desaparición forzada en Colombia, Bogotá.

Cifuentes, E. (2020). Territorialidades construidas en el contexto de la materialidad de la desaparición forzada en el departamento de Antioquia, entre 1993 y 2016. Universidad Pedagógica y Tecnológica de Colombia-Instituto Geográfico Agustín Codazzi, Bogotá.

Cifuentes, E. \& Avendaño, J. (2020). Geografías del conflicto: geometrías del poder en el contexto de la materialidad de la desaparición forzada, en el Departamento de Antioquia, Colombia, entre 1993 y 2016, Biblio3W, Revista Bibliográfica de Geografía y Ciencias Sociales, XXV(1302), Barcelona: Universidad de Barcelona.

Cifuentes, E. \& Ramírez, D. (2014). El fenómeno de la desaparición en mujeres en Colombia, 2009-2014, (1), 307- 349, Instituto Nacional de Medicina Legal y Ciencias Forenses. Masatugó, Bogotá.

El Colombiano (9 de mayo de 2011). El reservado caso de los 10 secuestrados de Sopetrán. Recuperado de https://www.elcolombiano.com/blogs/revelacionesdelbajomundo/ el-reservado-caso-de-los-10-secuestrados-de-sopetran/3429

El Tiempo (23 de agosto de 2007). Hallan fosa con 10 restos humanos en mina de oro de Amalfi. Recuperado de https://www.eltiempo.com/archivo/documento/CMS-3692356

Giraldo, J. (2015). Aportes sobre el origen del conflicto armado en Colombia, su persistencia y sus impactos. Contribución al entendimiento del conflicto armado en Colombia, Comisión Histórica del Conflicto y sus Víctimas. Ediciones desde abajo.

Luna, A. (2010). La concepción del espacio geográfico. Corrientes actuales y metodología del trabajo geográfico. Sección temario de oposiciones de Geografía e Historia. Proyecto Clio. Recuperado de http://clio.rediris.es/n36/oposicones/tema01.pdf

Observatorio de Derechos Humanos y Derecho Humanitario (2012). Desapariciones forzadas en Colombia. En búsqueda de la justicia. Documentos temáticos, (6), 55. Recuperado de http://www.oidhaco.org/uploaded/content/article/911764807.pdf

Santos, M. (1986). Por uma Geografia nova. Da crítica da Geografia a uma Geografia Crítica. Sao Paulo: Hucitec. En Silveira, M. (2013). Tiempo espacio en geografía: dilemas y reflexiones. Geografía Norte Grande, 9-29.

Segura, J. \& Ramírez, D. (2015). Comportamiento del fenómeno de la desaparición. Colombia. Forensis, 17(1), 287-321, Instituto Nacional de Medicina Legal y Ciencias Forenses. Bogotá.

Silveira, M. (2013). Tiempo espacio en geografía: dilemas y reflexiones. Geografía Norte Grande, 9-29. 